\title{
Redistributive Consequences of Abolishing Uniform Contribution Policies in Pension Funds
}

\author{
Damiaan H. J. Chen ${ }^{1,2,4}$. Sweder J. G. van Wijnbergen ${ }^{1,2,3,5}$ \\ Published online: 25 May 2020 \\ (c) The Author(s) 2020
}

\begin{abstract}
In a pension system with uniform policies for contribution and accrual, each participant has the same contribution rate and accrual rate independent of the age at the time of payment. Although a common practice for public sector pension plans in many countries, this is not actuarially fair because the investment horizon of young participants is longer than the investment horizon of the elderly. We show the unintended redistributive intergenerational effects of a uniform contribution system and the consequences of switching from uniform policies to an actuarially fair system, first analytically in a stylized model with three overlapping generations. We then quantify these effects in a detailed model with multiple overlapping generations, realistic parameters and detailed information on the income distribution, calibrated on the Dutch funded pension system. Our base estimate shows that the transition effect of abolishing uniform policies for an actuarially fair system is about 37 billion euros (5\% of the Dutch GDP) for an interest rate of $1 \%$ (the market interest rate ultimo 2017), but only 11 billion euro for an interest rate of $0 \%$ (the market interest rate as of July 2019). For each cohort, the redistributive effects are less than $5 \%$ of their total pension. We show that a system with uniform policies implies a transfer of about 10 billion euros from poor to rich.
\end{abstract}

Keywords Uniform policies · Pension funds · Transition · Income inequality

JEL Classification G23 · J32

\footnotetext{
We thank Netspar for funding this research with the Individual Research Grant. Furthermore, we are grateful to Casper van Ewijk, Marcel Lever, Sander Muns and Bas Werker for useful comments to earlier versions of this paper. We are also thankful for the comments of the Netspar Research Assembly participants.
}

Sweder J. G. van Wijnbergen

s.j.g.vanwijnbergen@uva.nl

Extended author information available on the last page of the article 


\section{Introduction}

Current Dutch pension reform plans aiming at transforming the second pillar from a DB into a more DC-like system also call for abolishing the uniform policy pension system (UPPS). A UPPS consists of uniform contribution rates and uniform accrual rates which are equal for all participants without taking into account the participant's age at the time of payment. The participant accumulates pension rights equal to the accrual rate times the pension base wage. For accumulating this pension, the participant pays the corresponding contribution rate times the pension base wage. Most DB pension schemes use such a contribution model, for example the public sector pension plans in Australia, Canada, Germany, the Netherlands, Norway and Switzerland, the Universities Superannuation Scheme in the U.K. and the sub-national civil servants' plans in the U.S. (Ponds et al. 2011; Westerhout et al. 2014; OECD 2001; Chen et al. 2017). So the problems created by UPSS are of much wider interest than to the Dutch alone. In this paper we analyze and quantify the transitional problems that need to be confronted when abolishing the system.

Under the UPPS, young people pay the same (undiscounted) as older people while getting the same pension entitlements, despite the fact that contributions of young people earn investment returns much longer, which implies higher expected cumulative investment returns. Hence, in a normal market with positive interest rates, an actuarially fair approach should for equal contributions provide a higher level of pension accrual to young people than to older people, or let the young pay less for equal accrual rights (see Fig. 1a and b). Therefore, younger workers subsidize older generations under the UPPS, assuming that they, once old, will in turn be subsidized likewise by future young generations. So a UPPS introduces a PAYG-element within the funded pension scheme, with young people paying for the elderly. Such an intergenerational contract is not really possible in a DC system, hence its intended abolishment is part of the Dutch pension reform plans.

The prospect for the currently young of receiving subsidies in the future to compensate for the subsidies they have already paid constitutes an implicit debt to the current young generations which is rolled over to future generations. Possibly the UPPS system was introduced to allow older people to accrue more pension rights during the early period of the funded pension scheme (second pillar). Whether intentionally or not, the first generation of older workers has gained too much and the implicit debt can be considered as the rolled-over funding gap of this initial payment to that first generation (the "first generation" problem).

Under a UPPS, a young person at the beginning of his working life begins without a claim on future generations, because he/she has not paid anything yet, so has not paid too much either. However, as the participant becomes older, he/she slowly builds up that claim up to a turning point. In Fig. 1, the turning point is at age 47. 

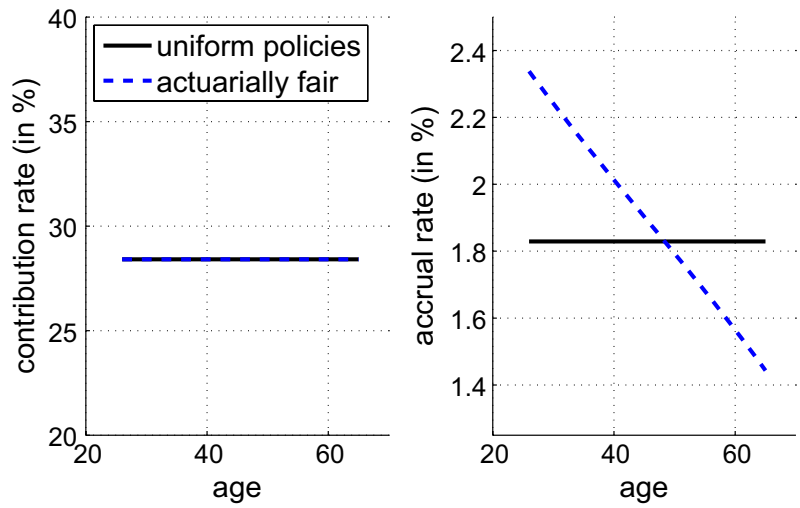

(a) Fixed contribution rate
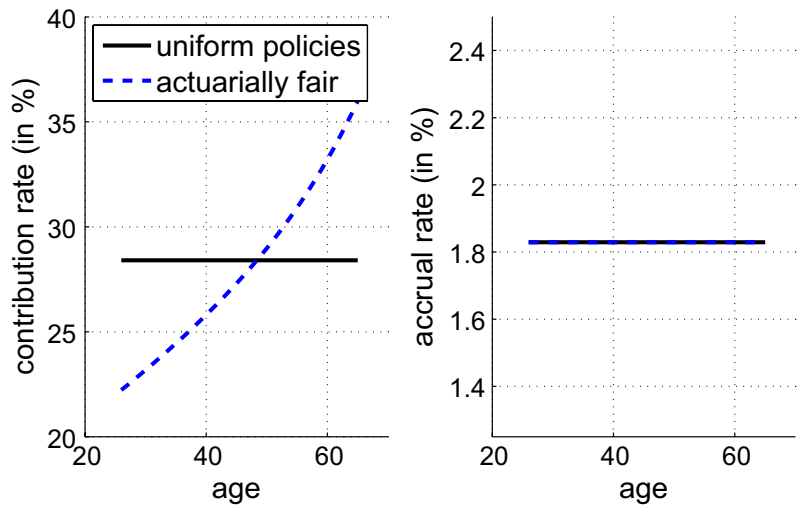

(b) Fixed accrual rate

Fig. 1 Illustration of the differences between a uniform policy pension system and two actuarially fair pension systems Note: these graphs are generated based on the parameter Set 1 from Table 3. Particularly, the results are sensitive to the interest rate parameter, which is here set at $r=1 \%$

After that, that total claim slowly declines again as the now older participant receives a subsidy from the new young working cohorts, until all claims are redeemed when the retirement age has been reached. So if that claim eventually gets extinguished, why is the UPPS nevertheless considered a problem?

Problematic Features of a UPPS First of all uniform policies are problematic because of the undesired redistribution effects that they trigger in practice. One redistribution effect is related to income inequality. Income inequality between young people is smaller than between older people, ${ }^{1}$ highly educated young people

\footnotetext{
${ }^{1}$ See Bonenkamp (2007) and Lever et al. (2013) for early studies on the relationship between socioeconomic status and redistribution effects in the second pillar.
} 
can expect a steeper wage profile over their life than low-skilled young people. And the associated skill premium is the main driver of income inequality, so highly educated people will eventually earn higher incomes, but will also benefit more from the subsidy they will receive when old than the less educated, and therefore lower income groups, will receive under the UPPS. Since the contribution rate is uniform and set in such a way that total contributions equal the total discounted value of accrued pension rights, there is redistribution of income from participants with a flat wage profile to participants with a steep wage profile. The latter group consists mostly of high skilled workers with higher wage income, so this transfer flows from the relatively poor to the relatively rick. These presumably unintended transfers between groups of participants make the pension system vulnerable (Boeijen et al. 2006).

A problem that has become more relevant recently emerges during labor market transitions if those transitions are from inside the coverage of the pension system to outside of it. This is in particular an issue when switching from a regular labor contract incorporating pension fund contributions towards a status as self employed outside the funded pension system. These transitions are happening on a large scale mid career, at about the turning point where the contributor switches from a payer to a receiver of the subsidy under the UPPS just at the time they move out of the system. Therefore, they actually lose the majority of future subsidies they would have obtained from the future young generations if they could have stayed inside the system. The PAYG chain is broken for the individual who switches to a self employed status where he/she no longer participates in the UPPS.

The same problem occurs, although to a lesser extent, when the working career is interrupted by periods of unemployment. Unemployment is typically followed by lower wages after reintegration, which, empirical evidence shows, will not be recovered in later years. Hence, redistribution also occurs between more and less successful employees. These labor market related problems have become much more relevant in recent years, due to increased labor mobility.

Another issue in many countries is that when the population growth rate goes down, due to an ageing society, the per capita burden on the young generations to subsidize the older generations becomes larger and larger, until the population growth rate stabilizes again. ${ }^{2}$

A final problem with the UPPS occurs when structural pension reforms are being envisaged, as is now the case in the Netherlands. One of the options is a transition to a defined contribution (DC) system, in which intergenerational contracts such as those underlying the UPPS have no place: with a pure individual or cohort specific DC system, there is no intergenerational risk-sharing at all. The question then arises how to deal with the outstanding claims of current workers on future young people.

So it is clear that the UPPS is (i) problematic in modern labor markets, (ii) complicates pension reforms and (iii) causes undesirable income redistribution effects from participants with a flat wage profile to participants with a steep wage profile,

\footnotetext{
2 This is beyond the scope of this paper, as we focus on the valuation of abolishing the UPPS and consider a range of constant population growth rates.
} 
which in practice means from poor to rich. Hence the plan to switch to an actuarially fair system. To goal of this paper is to quantify the redistribution effects from low income/low skilled workers to high income/high skilled workers and the generational effects that arise when abolishing the UPPS. We do this by calibrating a model with overlapping generations to the Dutch pension scheme and its participants.

Modeling the Cohort Specific Losses of Abolishing the UPPS An actuarially fair system can be set up in two different ways which are equivalent in terms of market value: a system with (i) degressive accrual rates (descending with age) and uniform contribution rates as illustrated in Fig. 1a, or one with (ii) progressive contribution rates (ascending with age) and uniform accrual rates as illustrated in Fig. 1b. In our modelling exercise we assume the latter option is adopted after abolishing the UPPS, but in terms of market value these are similar.

Simply closing the UPPS when switching to such a new system implies that any outstanding claims are no longer rolled over from generation to generation. As we saw, under the UPPS young people subsidize the elderly, expecting to be compensated once they are older by the then young, thereby creating an implicit debt, which is rolled over year-on-year. ${ }^{3}$ But abolishing the UPPS just like that (without compensation to current generations in their working life), implies that those current working generations actually have to bear the full burden of this implicit debt, as they are then the last in the chain. After all, they have subsidized the old in their earlier working years, but have not yet received all those subsidies back in the second part of their working life. Only those who have already retired at the time of the switch have no outstanding claim left since they have completed the cycle. Hence, simply abolishing the UPPS will involve a redistribution between current and future working generations. The latter benefit when the Aaron condition holds, as this implies a higher return in a funded pension scheme than in a PAYG scheme (Aaron 1966) and they no longer have to pay for any rolled-over implicit debt. This way, future generations need to pay a lower contribution rate in order to obtain the same level of pension benefits, which we refer to as the "contribution reduction" in the remainder of this paper.

Abolishing the UPSS thus gives rise to the question who should be charged for this implicit debt. The current system rolls the implicit debt over to future generations of participants, the as yet unborn or those already born but too young to already have started their working life. At the other extreme is an outright debt default, which would shift the burden to different degrees per cohort to those cohorts currently at work.This is in the end a political decision outside the scope of this paper. However, before a decision can be made on allocating the debt service of what is now still an implicit debt, one needs to quantify the generational effects of abolishing the UPPS and identify its main determinants, and that is the main goal of this paper.

\footnotetext{
${ }^{3}$ Note that this rolling over of implicit debt actually is not a Ponzi game. Since the debt is rolled over without accruing interest, its value goes to zero in discounted value terms in the long run. Hence, rolling over the implicit debt does not imply a Ponzi-scheme (Sinn 2000).
} 
Backward Looking or Forward Looking Approach For determining the transition effects, we can apply a backward looking or forward looking methodology. The backward looking methodology considers individually or group-specifically what investment return would have been achieved in the past, assuming there would not have been a UPPS. Forward looking implies that we determine using a formal model how much implied debt has been built up by different cohorts given assumptions about market conditions, demographics and the structure of the pension scheme. The backward methodology has a number of drawbacks.

A first problem with the backward looking approach is that one then should arguably correct for other pension reforms and changes in regulation that have taken place in the past as well. In a forward looking approach, we can simply start by taking the current accumulated pension entitlements, which already incorporate the past pension reforms and changes in regulation.

A second consideration against the backward looking approach is the complex data requirements and the practical complications that would arise if one would attempt to determine to what extent individuals or groups have built up claims under the UPPS. As we will explain in the next paragraph, the forward looking approach requires a valuation at a single moment based on the market interest rates at that moment, while the backward looking approach requires a valuation at every moment that participants accrue pension entitlements, based on market interest rates corresponding to each of these moments.

Due to these considerations, we apply the forward looking methodology in this paper.

Valuation of the Transition Effects If the UPPS is abolished, implied future claims will expire. The basis for valuing these future claims is the market value of those commitments at the time of abolition. Nominal defined benefit (DB) pension rights can be replicated by financial instruments available in the capital markets outside the pension fund, which makes market valuation an objective measure for valuating the transition effects. In particular, this implies that we need to use the "safe market interest rate", as derived from the swap curve. Any other approach implies potentially large value transfers from young to old (at a higher interest rate than the one that follows from the swap curve) or from old to young (using a lower interest rate than the one that follows from the swap curve). This implies using the risk neutral distribution, which in turn means that risk has been priced in, people will be compensated for bearing risk based on the market price of risk: the use of risk neutral pricing (RNP) means that comparisons based on market value between different portfolios are corrected for differences in risk characteristics, using market prices for the relevant risks. For example, equities have a higher expected return than government bonds, but are more risky. Hence, the risk premium compensates for taking risks, based on the market prices of the corresponding risks. The use of RNP is necessary if we want to calculate the market consistent value of claims which are lost by abolishing the UPPS.

In practice, there are other policies which are likely to also have redistributive effects, for example the possibility that pensions are increased or reduced due to the solvency position of the pension fund. This would require a stochastic analysis. We 
choose to apply a deterministic approach, since we focus on abolishing the UPPS only. This way we can better gain the intuition of the economic features in a general setting, as there are no cross-effects with other (country) specific pension policies.

Similar deterministic analyses are done by Van Ewijk (2017), Werker (2017), while Lever and Muns (2017) analyze this topic using a stochastic analysis. Our paper contributes to these studies in several ways. First, we quantify the subsidy from the participants with a flat wage profile to participants with a steep wage profile which is present under the UPPS. Since low skilled people have a flat wage profile and high skilled people a steep profile and skill premia are the main driver of income inequality in modern times, this is in fact a subsidy from poor to rich, or more accurately, from low income to high income households. Second, we analyze the transition effects of abolishing the UPPS in two ways: (i) analytically: by simplifying the model to three overlapping generations (OLG) we gain insights by algebraically investigate the effects of the main parameters, and (ii) numerically: with multiple overlapping generations and realistic assumptions we obtain numerical outcomes from our model, which are a more realistic representation of the transition effects of abolishing the UPPS. Although we use the Dutch pillar-2 pension system as an example, most public pension systems in the world have a comparable UPSS structure, so our analysis should be of wider interest than to the Dutch alone.

In the remainder of this paper, we present a discrete time OLG model in which the various economic factors involved in abolishing the UPPS can be analyzed (Sect. 2). In order to clarify the intuition behind these economic features, we analyze a simplified version of that model in Sect. 3, whith only two working generations (the young and the old) and one retired generation. Using this simplification, this 3-OLG model is analytically solvable. In Sect. 4 we consider a more realistic setting that takes into account at least forty working generations and twenty retired generations simultaneously. Section 5 summarizes the main conclusions. Mathematical derivations are shown in "Appendix".

\section{A Discrete Time OLG Model}

\subsection{Model Structure}

Demography We define an overlapping generations (OLG) model, with $n$ working generations and $m$ retired generations. Generations become older after each period: a generation with age $i$ becomes the generation with age $i+1$ one period later. In this model the youngest working cohort has the age $i=1$. The reader may want to add 25 to get a calendar year age.

In order to analyze the transfers from participants with a flat wage profile to participants with a steep wage profile, we distinguish two types of workers: one with high $(H)$ and one with low $(L)$ productivity, reflecting differences in educational achievement. High productivity workers have a steeper wage profile. Define 
$u_{t}^{k}=\left(u_{1, t}^{k}, u_{2, t}^{k}, \ldots, u_{n+m, t}^{k}\right)$ as the vector with elements $u_{i, t}^{k}$, which reflects the number of people from a generation with age $i$ and productivity type $k \in\{H, L\}$ at time $t$. With constant population growth $g$ we get

$$
u_{i, t+1}^{k}=(1+g) u_{i, t}^{k}, \forall i \in\{1,2, \ldots, n+m\} .
$$

We define $\alpha \in[0,1]$ as the fraction of the working population of the high productivity type.

Wage The pension base of a participant is the amount over which he/she accrues pension rights and pays contributions (we refer to the pension base as the wage of the participant although in practice there are likely to be differences between the wage paid and the pension base. ${ }^{4}$ The wage of a participant with type $k$ age $i$ at time $t$ is defined as $w_{i, t}^{k}$. For working generations, wages is strictly positive, $w_{i, t}>0, \forall i \in\{1,2, \ldots, n\}$. Pensioners have no wage, so we have that $w_{n+i, t}=0, \forall i \in\{1,2, \ldots, m\}$.

The wage of a cohort changes over time for two reasons: wage inflation and career development. Career development depends on the productivity type $k \in\{H, L\}$ (high or low):

$$
w_{i+1, t}^{k}=w_{i, t}^{k}\left(1+c^{k}\right), \forall i \in\{1,2, \ldots, n-1\} .
$$

Overall wage inflation equals $\pi$ so the wage for a participant with age $i$ is

$$
w_{i, t+1}^{k}=w_{i, t}^{k}(1+\pi) .
$$

Pension Rights Pension liabilities are valued as the net present value of the pension benefits based on the current pension rights. The indexation rate $z$ is guaranteed, however under the benchmark parameter setting of this paper we consider zero indexation $(z=0)$. Guarantees are valued using the risk-free nominal interest rate $(r)$. Using these definitions, the price for one euro pension accrual for the cohort with age $i$ can be expressed by an annuity factor $K_{i}$. We break the formula up in two parts for transparancy. First the value of one unit extra for the duration $m$ at the beginning of the pension period is:

$$
K=\sum_{j=1}^{m} q^{j},
$$

which implies the following value of one unit accrual for a working generation of age $i$ :

\footnotetext{
${ }^{4}$ In Sect. 4 we calibrate the model to match the total pension base of the Dutch economy.
} 


$$
K_{i}=q^{n-i} K=q^{n-i} \sum_{j=1}^{m} q^{j}, \quad i \in\{1,2, \ldots, n\} .
$$

For an already retired cohort, the duration is less than $m$, yielding

$$
K_{i}=\sum_{j=0}^{m+(n-i)} q^{j}, \quad i \in\{n+1, n+2, \ldots, n+m\} .
$$

The parameter $q$ is given by

$$
q=Q \frac{1+z}{1+r}
$$

The parameter $Q$ scales the factors $K_{i}$ for the discount rate used to calculate the pension contributions. For $Q=1$ the price of pension accrual is actuarially fair. For other values of $Q$, the pension rights are discounted at a different rate and as a consequence the pension contributions will not be actuarially fair. As an example, when there is guaranteed positive indexation $(z>0)$, but the contributions are based on nominal pension rights without indexation, then we have $q=\frac{1}{1+r}$, which implies that $Q=\frac{1}{1+z} \neq 1$. Another example is to discount with expected investment returns, instead of the risk-free rate. In that case we have $Q=\frac{1+r}{1+r+\mu}<1$, where $\mu>0$ denotes the risk premium of the investment portfolio.

The accrued pension rights of the cohort with age $i$ are defined as $B_{i, t}$. Working cohorts accrue new pension rights with accrual rate $\rho_{i, t}^{k}>0$, which is a fraction of their wage. Then, the pension rights increase with indexation and accrual as follows

$$
\begin{aligned}
B_{i, t}^{k} & =(1+z) B_{i-1, t-1}^{k}+\rho_{i, t}^{k} w_{i, t}^{k}, \forall t \text { and } i \in\{1,2, \ldots, n+m\} \\
\text { with } B_{0, t}^{k} & =0, \forall t .
\end{aligned}
$$

Since the wage is zero during retirement, pension rights simply with a rate $(1+z)$ only for pensioners. The obtained pension benefit for a pensioner with type $k$ and age $i$ at time $t$ is equal to $(1+z) B_{i, t}^{k}$.

The Uniform Policy Pension System (UPPS) In the UPPS, both the accrual rate and the contribution rate is uniform, so independent of age and independent of productivity type. Hence, each participant has the same accrual rate, i.e. $\rho_{i, t}^{k}=\rho$, so we can write $\rho$ as a scalar instead of a vector.

In order to obtain the uniform contribution rate, we first define the total pension base as

$$
P B_{t}=\sum_{i=1}^{n}\left(u_{i, t}^{H} w_{i, t}^{H}+u_{i, t}^{L} w_{i, t}^{L}\right)
$$

The term $u_{i, t}^{k} w_{i, t}^{k}$ represents the wage of the group with age $i$ and productivity type $k$ at time $t$. Hence, (9) reflects the wage of all working individuals at a given time $t$. Then the uniform contribution rate $P^{U}$,defined as the uniform rate that sets the value 
of the pensiuon rights that are accrued in a given year equal to the contributions in that same year:

$$
P^{U} * P B_{t}=\sum_{i=1}^{n}\left(\rho u_{i, t}^{H} w_{i, t}^{H} K_{i}\right)+\sum_{i=1}^{n}\left(\rho u_{i, t}^{L} w_{i, t}^{L} K_{i}\right) .
$$

The term $\rho u_{i, t}^{k} w_{i, t}^{k}$ represents the wage of the group with age $i$ and productivity type $k$ at time $t$ multiplied by the accrual rate $\rho$, this is the total accrual of pension rights at time $t$ for this specific group. By multiplying this by the factor $K_{i}$, we obtain the discounted value of the total accrual of this group in year t. Hence, at a given time $t$, the right hand side of (10) reflects the discounted value of pension accrual of all working generations $i$ and both productivity groups $k$. The aggregate contributions received by the pension fund equals $P^{U} * P B_{t}$, which is the left hand side of (10). In order to obtain a financially sound balance, the pension fund should receive the same amount from pension contributions as it hands out pension accruals in that same year, which is the equality imposed by 10 . It is then simple to derive the uniform contribution rate $P^{U}$ itself:

$$
P^{U}=\frac{\rho \sum_{i=1}^{n}\left(u_{i, t}^{H} w_{i, t}^{H}+u_{i, t}^{L} w_{i, t}^{L}\right) K_{i}}{P B_{t}} .
$$

Pension Fund The assets of the pension fund $A_{t}$ evolve as

$$
A_{t+1}=(1+r)\left[A_{t}+P^{U} * P B_{t}-\sum_{i=n+1}^{n+m}\left(u_{i, t}^{H} B_{i, t}^{H}+u_{i, t}^{L} B_{i, t}^{L}\right)\right] \text {. }
$$

The assets increase with rate of return $r$. The term $P^{U} P B_{t}$ denotes the received contributions in year $t$ (as in (10)) and the summation term represents the total pension benefits payed out to the retirees in year $t$.

The liabilities of the pension fund are equal to

$$
L_{t}=\sum_{i=1}^{n+m} K_{i}\left(u_{i, t}^{H} B_{i, t}^{H}+u_{i, t}^{L} B_{i, t}^{L}\right) .
$$

Since we have a constant inflow and outflow of participants, such that new accrual cancels out against payed out benefits, this can be shown to follow the following recursive relation (cf "Liabilities in Recursive Form" in Appendix 1):

$$
L_{t+1}=(1+g)(1+\pi) L_{t} .
$$

The funding ratio is defined as the assets over liabilities

$$
F_{t}=A_{t} / L_{t} .
$$




\subsection{Redistributive Impact of Abolishing Uniform Contribution Policies: The Analytics}

When the UPPS is abolished and replaced by a system with actuarially fair contribution rates, the contribution rate becomes

$$
P_{i}=\rho K_{i}
$$

Assuming $q=Q \frac{1+z}{1+r}<1$ this results in contribution rates which are increasing with age. This is not an unlikely assumption. With an actuarially fair price of pension accrual we have $Q=1$. Then the assumption holds for $r>z$, which means that the rate of return should exceed the guaranteed indexation rate.

Net Value Transfers The retired generations have already paid and received the subsidies under the UPPS during their working life and are thus out of the system. Working cohorts have paid subsidies, but have not yet fully received the equivalent amount in subsidies as they still have some years to go before retirement. Hence, the current working cohorts might be negatively affected by abolishing the UPPS. Against that effect is the consequence of switching to an actuarially fair system, that the contribution rate can be reduced because contributing cohorts no longer pay for the implicit debt.

Now we make two simplifying assumptions, which we relax from Sect. 4.3 onwards. First, we normalize the wage of the youngest working cohort at time $t=0$, so we have $w_{1,0}^{H}=w_{1,0}^{L}=1$. Second, we normalize the oldest working cohort to $u_{n, 0}^{H}+u_{n, 0}^{L}=1$, which implies that $u_{n, 0}^{H}=\alpha$ and $u_{n, 0}^{L}=1-\alpha$. "Net Value Transfer" in Appendix shows that the net value transfer $(N V T)$ to a generation of age $j$ at time $t$ with type $k$ is obtained as

$$
\begin{aligned}
N V T_{j, t}^{k} & =\Xi_{j, t} u_{n, 0}^{k} \sum_{i=\max (j-1,0)}^{n-1}\left(\frac{(1+\pi)\left(1+c^{k}\right)}{q(1+r)}\right)\left(q^{i} \frac{\sum_{l=0}^{n-1} \frac{\chi_{l}}{q^{l}(1+g)^{l}}}{\sum_{l=0}^{n-1} \frac{\chi_{l}}{(1+g)^{l}}}-1\right), \\
\text { with } \Xi_{j, t} & \left.=\rho\left(\frac{(1+g)(1+\pi)}{(1+r)}\right)^{1-j}(1+\pi)^{t}(1+g)^{t+n-1} l=n\right] m+n-1 \sum_{l=n}^{[} q^{l}, \\
\text { and } \chi_{i} & =\alpha\left(1+c^{H}\right)^{i}+(1-\alpha)\left(1+c^{L}\right)^{i},
\end{aligned}
$$

where $\chi_{i}$ stands for the cumulative wage increase received by cohort $i$ averaged over the two labor types.

Abolishing UPPS obviously is a "zero-sum game", since the sum of the net value transfers cancel out:

$$
\sum_{j=-\infty}^{n}\left(N V T_{j, t}^{H}+N V T_{j, t}^{L}\right)=0 .
$$

Setting the lower bound for $j$ at minus infinity implies that all future generations are incorporated too. This is necessary because under the UPPS the implicit debt owed 
to the currently young is essentially rolled over into the indefinite future (although it approaches zero in discounted value terms, so this is not a Ponzi game).

Even after substantial rewriting the expression in (17), it is still not easy to interpret without further simplification. Therefore, we consider several special cases, to get useful insights from (17). First, we consider the case $q=1$, i.e. $Q(1+z)=(1+r)$. Then, it follows from (17) that there is a zero net value transfer: $N W T_{j, t}^{k}=0 \forall j, t, k$. This is because the value of the contributions and benefits are equal with and without the UPPS. To be more precise, when $Q=1$ and $r=z$, the UPPS is actually actuarially fair, as the pension rights are increased by the risk free rate. In this special case abolishing the UPPS implies no net value transfers between different cohorts.

Second, we consider the case $q<1$, i.e. $(1+r)>Q(1+z)$. Under this setting there is a PAYG-element in the UPPS, as the young generations subsidize the old generations compared to an actuarially fair system, i.e $P^{U}>P_{i}$ for low $i$. We need to simplify the model further to gain this insight from (17), which we do in the next section by considering three overlapping generations.

Third, we can also learn from the last term in $\Xi_{j}$ which is $\left(\frac{(1+g)(1+\pi)}{(1+r)}\right)^{1-j}$. According to the well-known Aaron condition $((1+r)>(1+\pi)(1+g))$ a funded pension scheme implies a higher return than is implicit in a PAYG scheme (Aaron 1966). However, when the total wage growth is equal to the interest rate $((1+r)=$ $(1+\pi)(1+g))$, then we get for future generations, i.e. $j \leq 1$, the following:

$$
N V T_{j, t}=N V T_{j, t}^{H}+N V T_{j, t}^{L}=0 .
$$

So when the Aaron condition holds with equality, there is no benefit for future generations by no longer having to pay for the implicit debt, since then the (implicit) return on the PAYG-element is equal to the interest rate.

\section{Abolishing UPPS: Sensitivity Analysis for Two Working Generations and One Retired Generation (3-OLG)}

To get to comprehensible analytical results and gain intuition, we first investigate a stylized version of the model with two working cohorts and one retired generation. Two working generations is the required minimum to investigate effects of the UPPS. Hence, we assume $n=2$ and $m=1$. This way, the uniform contribution rate equals

$$
P^{U}=\rho q \frac{(1+g) q+\chi_{1}}{1+g+\chi_{1}} .
$$

The net value transfer (17) for generation $j$ with type $k$ then becomes 

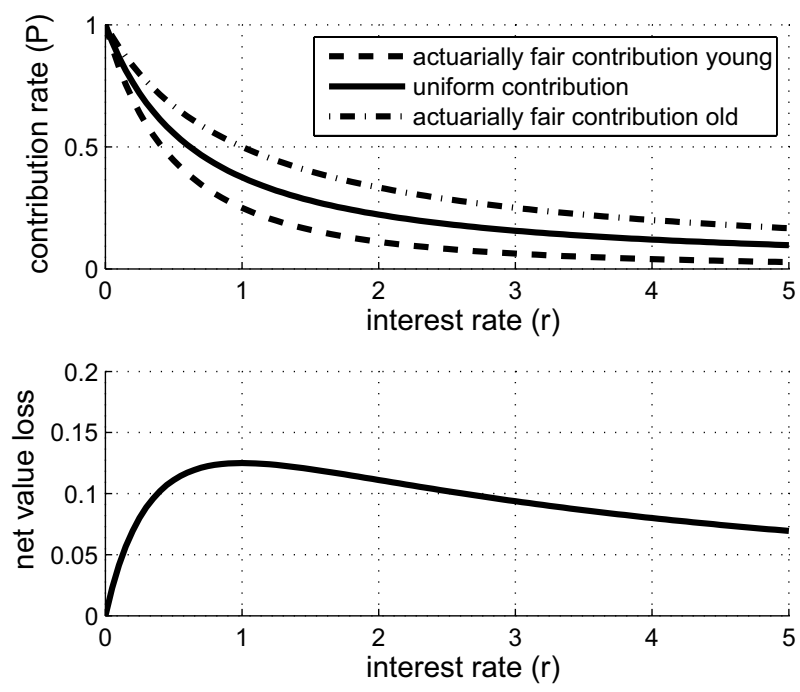

Fig. 2 Contribution rates and net value loss of the oldest working cohort as a function of the interest rate $\left(\rho=Q=1, g=z=\pi=c^{H}=c^{L}=0\right)$ Note: these are interest per period in a 3-OLG setting. If one period is 20 years, then an interest rate of $r=100 \%$ implies an annual interest rate of $\left(1+r^{*}\right)^{1 / 20}-1 \approx 3.5 \%$

$$
N V T_{j, t}^{k}= \begin{cases}\rho q(q-1) \frac{(1+\pi)^{t}(1+g)^{t+1}}{1+g+\chi_{1}} u_{2,0}^{k}\left(1+c^{k}\right), & \text { for } j=2, \\ \rho q(q-1) \frac{(1+\pi)^{t}(1+g)^{t+1}}{1+g+\chi_{1}}\left(\frac{(1+g)(1+\pi)}{(1+r)}\right)^{1-j} u_{2,0}^{k} \frac{\left(1+c^{k}\right)(1+\pi)(1+g)-\chi_{1}(1+r)}{(1+r)}, & \text { for } j \leq 1 .\end{cases}
$$

From this analytical expression for the net value transfer we can obtain several insights. We first focus on the oldest working cohort $j=2$ and second we discuss the youngest cohort and all future cohorts $j \leq 1$.

Due to the term $(q-1)$, observe that the net value transfer equals zero for all types when $q=1$, i.e $(1+r)=Q(1+z)$, because the value of the contributions and benefits are then equal with and without the UPPS. Second, we have that for $r \rightarrow \infty$, then $q \rightarrow 0$ and, hence, we obtain $\lim _{r \rightarrow \infty} N V T_{2, t}^{k}=0$. In other words, the net value transfer of older generations converges to zero when the interest rate goes to infinity. This implies that for an extremely high interest rate, the older generations are barely affected by abolishing UPPS, because then the contribution rate for a fixed level of pension accrual becomes extremely low. Third, the minimum ${ }^{5}$ net value transfer of older generations is obtained at an interest rate of $r^{*}=2 Q(1+z)-1$, with minimum $N V T_{2, t}^{k}=-\frac{\rho u_{2, t+1}^{k}(1+\pi)^{t}\left(1+c^{k}\right)}{4\left(1+g+\chi_{1}\right)}$. Suppose that $Q=\frac{1}{1+z}$ and one period is 20 years, then the 3-OLG setting implies that people work for 40 years and are retired for 20 years. This interest rate is $r^{*}=100 \%$ over a 20 year period, which is on an annual

\footnotetext{
$\overline{5}$ First-order condition of $q(q-1): \frac{\partial\left[(1+r)^{-1}-Q(1+z)(1+r)^{-2}\right]}{\partial r}=0 \Longleftrightarrow r=2 Q(1+z)-1$.
} 
Fig. 3 Net value transfer of the youngest generation as a function of the interest rate $(r)$ and wage growth $(\pi)$ $\left(Q=\rho=1, z=g=c^{H}=c^{L}=0\right)$

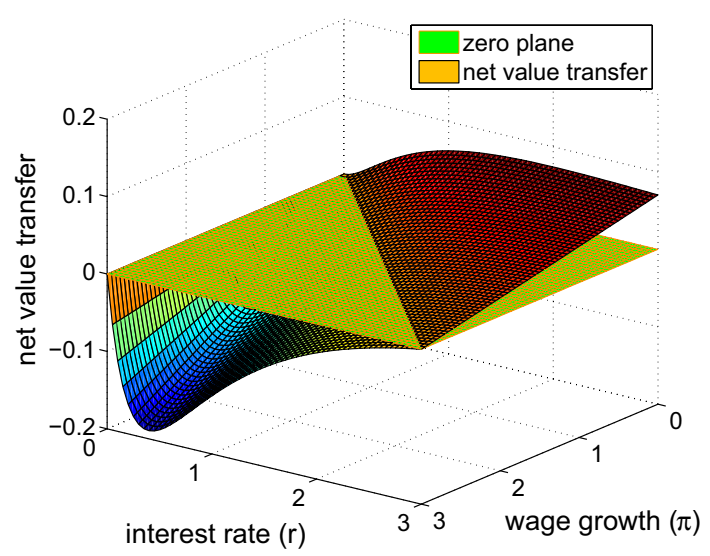

Table 1 Net value transfer of the youngest generation as a function of the interest rate $(r)$ and wage growth $(\pi)$ $\left(Q=\rho=1, z=g=c^{H}=c^{L}=0\right)$

\begin{tabular}{lllll}
\hline $\begin{array}{l}\text { Net value transfer } \\
\text { youngest generation }\end{array}$ & $\pi=0$ & $\pi=1$ & $\pi=2$ & $\pi=3$ \\
\hline$r=0$ & 0 & 0 & 0 & 0 \\
$r=1$ & 0.063 & 0 & -0.063 & -0.125 \\
$r=2$ & 0.074 & 0.037 & 0 & -0.037 \\
$r=3$ & 0.070 & 0.047 & 0.023 & 0 \\
\hline
\end{tabular}

basis in this example equal to an interest rate of: $\left(1+r^{*}\right)^{1 / 20}-1 \approx 3.5 \%$. To summarize these three observations, assuming $Q=\frac{1}{1+z}$, the older generations have a zero net transfer when the interest rate is zero or when it is infinity, while the net transfer is minimized at an annual interest rate around $3.5 \%$ in this simplified setting.

We show these results in Fig. 2, where the contribution rates and the net value loss of the older generation are presented as a function of the interest rate. The contribution rates decrease with the interest rate. For $r>r^{*}$ both the uniform and the actuarially fair contribution rates decrease towards zero and, hence, the differences decrease as well.

Similarly, we can also obtain insights from the net value transfer (20) for the youngest cohort and all future cohorts $j \leq 1$. First, when $q=1$ the net value transfer equals zero for all types again, because there is no difference between the value of the contributions and benefits with and without the UPPS. Second, the total net value transfer for a generation $j \leq 1$ is as follows 


$$
\begin{gathered}
N V T_{j, t}^{H}+N V T_{j, t}^{L}=\rho q(q-1) \frac{(1+\pi)^{t}(1+g)^{t+1}}{1+g+\chi_{1}}\left(\frac{(1+g)(1+\pi)}{(1+r)}\right)^{1-j} \chi_{1} \\
\frac{(1+\pi)(1+g)-(1+r)}{(1+r)} .
\end{gathered}
$$

Similar to Sect. 2.2, we observe from the last term that when the Aaron condition holds with equality, i.e. $(1+r)=(1+\pi)(1+g)$, the total net value transfer of each future generation is zero.

Similar to Sect. 2.2, the net value transfer for generations $j \leq 1$ from (20) equals zero for $q=1$ and for $(1+r)=(1+\pi)(1+g)$. By assuming $Q=\frac{1}{1+z}$, we have that when the Aaron condition is violated $((1+\pi)(1+g)>(1+r))$ and the interest rate is positive $(r>0)$, the net value transfer for future generations is actually negative. This implies that under certain settings, it can be beneficial for future generations to keep the PAYG component.

The results for the current youngest generation $(j=1)$ with $t=z=g=c^{H}=c^{L}=0$ and $\rho=Q=1$ are presented in Fig. 3 and Table 1, where we vary both the interest rate and the wage growth. Figure 3 and Table 1 show that the value transfer of the youngest generation is indeed zero when $r=0$ or $r=\pi$. Moreover, the value transfer is positive when $r$ is larger than $\pi$, because the Aaron condition strictly holds in this case $((1+r)>(1+\pi)(1+g))$. When $r<\pi$, the value transfer is negative.

\subsection{The UPPS and Implicit Subsidies from Low to High Skilled Workers}

Using the same stylized model we next analyze the transfers between type groups, in order to study the implicit redistribution from low to high skilled workers under the UPPS. Under the UPPS with $q<1$, the youngest working cohort pays a larger contribution rate than what is actuarially fair:

$$
\left(P^{U}-P_{1}\right)\left(u_{1, t}^{H} w_{1, t}^{H}+u_{1, t}^{L} w_{1, t}^{L}\right)=\frac{\rho q \chi_{1}}{1+g+\chi_{1}}\left(u_{1, t}^{H} w_{1, t}^{H}+u_{1, t}^{L} w_{1, t}^{L}\right)(1-q)>0 .
$$

However, one period later, this cohort becomes the oldest working cohort and then expects to pay a lower contribution rate than what is actuarially fair:

$$
\begin{aligned}
& \left(P^{U}-P_{2}\right)\left(u_{2, t+1}^{H} w_{2, t+1}^{H}+u_{2, t+1}^{L} w_{2, t+1}^{L}\right) \\
& \quad=\frac{\rho q(1+g)}{1+g+\chi_{1}}\left(u_{2, t+1}^{H} w_{2, t+1}^{H}+u_{2, t+1}^{L} w_{2, t+1}^{L}\right)(q-1)<0 .
\end{aligned}
$$

The group with the high type obtains a fraction $\frac{\alpha\left(1+c^{H}\right)}{\chi_{1}}$ of this subsidy when old, while the low type group gets the complement fraction $\frac{(1-\alpha)\left(1+c^{L}\right)}{\chi_{1}}$, so an individual high type participant gets $\frac{\left(1+c^{H}\right)}{\chi_{1}}$, while the low type participant gets $\frac{\left(1+c^{L}\right)}{\chi_{1}}$. Since the contributions of the two types are the same in the first working period (period one 
Table 2 Subsidies under the UPPS

\begin{tabular}{ll}
\hline Symbol & Subsidy \\
\hline$A 1$ & Subsidy from all young tohigh skilled old: \\
& $-N V T_{2, t}^{H}=\frac{\rho q(1+\pi)^{t}(1+g)^{t+1}}{\left(1+g+\chi_{1}\right)}(1-q) \alpha\left(1+c^{H}\right)$ \\
$A 2$ & Subsidy from all young to low skilled old: \\
& $-N V T_{2, t}^{L}=\frac{\rho q(1+\pi)^{t}(1+g)^{t+1}}{\left(1+g+\chi_{1}\right)}(1-q)(1-\alpha)\left(1+c^{L}\right)$ \\
$A 1+A 2$ & Subsidy from all young to all old: \\
& $T T E_{t}=-N V T_{2, t}=-N V T_{2, t}^{H}-N V T_{2, t}^{L}$ \\
$B 1$ & Subsidy to a high skilled participant: \\
& $\frac{-N W V_{2, t}^{H}}{\alpha}=\frac{\rho q(1+\pi)^{t}(1+g)^{t+1}}{\left(1+g+\chi_{1}\right)}(1-q)\left(1+c^{H}\right)$ \\
& Subsidy to a low skilled participant: \\
& $\frac{-N W V_{2, t}^{L}}{1-\alpha}=\frac{\rho q(1+\pi)^{t}(1+g)^{t+1}}{\left(1+g+\chi_{1}\right)}(1-q)\left(1+c^{L}\right)$ \\
& Perverse subsidy to a high skilled participant: \\
& $\frac{-N W V_{2, t}^{H}}{\alpha}-\frac{-N W V_{2, t}^{L}}{1-\alpha}=\left(c^{H}-c^{L}\right) \frac{T T E_{t}}{\chi_{1}}$ \\
& \\
& Perverse subsidy to all high skilled participants: \\
& $\alpha\left(\frac{-N W V_{2, t}^{H}}{\alpha 1-B 2)}-\frac{-N W V_{2, t}^{L}}{1-\alpha}\right)=\alpha\left(c^{H}-c^{L}\right) \frac{T T E_{t}}{\chi_{1}}$ \\
\hline &
\end{tabular}

wages are identical across types) and $c_{H}>c_{L}$, the UPPS implies a subsidy from participants with a flat wage profile to participants with a steep wage profile. This is sometimes called "perverse solidarity", since people who are more highly educated (and in practice healthier) profit more (Chen and Beetsma 2015; Bovenberg et al. 2006; Sutrisna 2010). In this paper therefore we refer to the "perverse subsidy", as the subsidy from participants with a flat wage profile to participants with a steep wage profile, as a consequence of the UPPS.

So compensating the old working cohorts for the excess payments in their first working period implies that participants with a steep wage profile obtain more compensation than participants with a flat wage profile, while they have paid the same subsidy in the past, since we assumed that wage when young is equal for both types $\left(w_{1, t}^{H}=w_{1, t}^{L}\right)$. The difference in received subsidy between a low type and high type participant of the old working cohort equals $T T E_{t} \frac{c^{H}-c^{L}}{\chi_{1}}>0$, where $T T E_{t}=-N W V_{2, t}$ denotes the total transition effect.

In one period the subsidy from young to old is at least $\operatorname{TTE}_{t} \frac{\left(1+c^{L}\right)}{\chi_{1}}$, while the high skilled workers get an additional subsidy of $T T E_{t} \frac{c^{H}-c^{L}}{\chi_{1}}$. Table 2 summarizes the different subsidies under the UPPS.

To get some intuition of these effects, suppose the high type group is half of the working population, i.e. $\alpha=0.5$, and the high type has double the wage of a low type in his second working period $\left(c^{H}=2\right.$ en $\left.c^{L}=1\right)$, then the subsidy from the young to the low skilled old is $\frac{4}{5} T T E_{t}$, while the high skilled get an additional 
Fig. 4 Risk-free yield curve based on the risk-free swap rate at September 30, 2017. Source: DNB (2017)

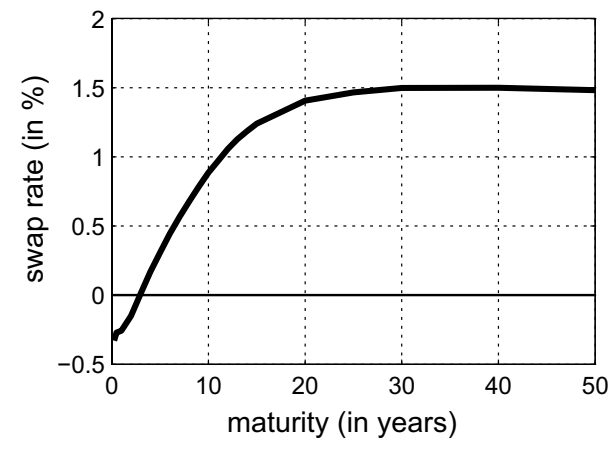

subsidy of $\frac{2}{5} T T E_{t}$. This example illustrates that one-third of the total transition effect for a participant with a steep wage profile consists of the perverse subsidy.

The problem is created because wage inequality is low when young (zero in our example) and high when old, while the uniform contribution rate is the same for all participants, independent of age and type. An alternative would be to differentiate between type, by considering a uniform contribution rate independent of age but for low and high skilled workers separately:

$$
P^{U, k}=\frac{\rho \sum_{i=1}^{n}\left(u_{i, t}^{k} w_{i, t}^{k} K_{i}\right)}{\sum_{i=1}^{n}\left(u_{i, t}^{k} w_{i, t}^{k}\right)}=\rho q \frac{(1+g) q+\left(1+c^{k}\right)}{(1+g)+\left(1+c^{k}\right)} .
$$

This alternative system favors the low skilled participants compared to UPPS, since there is no perverse subsidy. To be more specific, "Subsidy from Low to High Skilled Participants in 3-OLG Model" in Appendix shows that the uniform contribution rate for the type $k$ minus the original uniform contribution is given by:

$$
\begin{aligned}
P^{U, L}-P^{U} & =\frac{\rho q(1+g)}{\left(1+g+\chi_{1}\right)\left((1+g)+\left(1+c^{L}\right)\right)} \alpha(q-1)\left(c^{H}-c^{L}\right), \\
P^{U, H}-P^{U} & =\frac{\rho q(1+g)}{\left(1+g+\chi_{1}\right)\left((1+g)+\left(1+c^{H}\right)\right)}(1-\alpha)(q-1)\left(c^{L}-c^{H}\right) .
\end{aligned}
$$

From these equations we observe that when there is no difference between low and high skilled workers, i.e. $\alpha=0, \alpha=1$ or $c^{H}=c^{L}$, then there is no subsidy from one type to another. Again this also holds for $q=1$, as the value of the contributions and benefits are equal with and without the UPPS, so there are also no transfers between groups. 


\section{$4 \boldsymbol{n}$ Working Generations and $\boldsymbol{m}$ Retired Generations (multi-OLG): The UPPS in the Netherlands}

The 3-OLG model (with $n=2$ and $m=1$ ) provided analytical insights into the determinants of the transition effects, but is too simplified to provide quantitatively realistic estimates. We therefore switch from our simplified model to a more realistic OLG model, with $n=40$ working cohorts and $m=20$ retired cohorts. Note that in this model we give an alternative interpretation to age: the employees have the age of 1-40 and retirement starts at the age of 41. A more realistic interpretation is simply obtained by adding 25 years to these ages. We refer to the latter as the "real age".

\subsection{Calibration}

We calibrate the model on the Dutch economy, as the UPPS applies to the major part of the Dutch second pillar and there is broad support for replacing the UPPS by an actuarially fair system of contributions, so analyzing the associated transition effects is of substantial policy interest. Moreover, the recent coalition agreement of the Dutch government announced that it would elaborate on these plans. The Dutch second pillar is large, with total assets about twice the size of the Dutch GDP. Since at the time of writing the nominal funding ratios of Dutch pension funds are around $100 \%$, we assume that the indexation rate is zero $(z=0)$, because in the Netherlands the minimum funding ratio for providing is at circa $110 \%$. Figure 4 shows the riskfree yield curve based on the risk-free swap rate 2017 year end. Our model is a stylized version, because we do not distinguish between discount factors for liabilities with different maturities. In other words, we take a flat risk-free yield curve. Specifically, we assume that in our benchmark parameter setting the risk-free interest rate is $r=1.0 \%$. As shown in Fig. 4, this corresponds to the risk-free swap rate with maturity of 11 years.

We assume that the accrual rate equals $\rho=1.829 \%{ }^{6}$ We calibrate the model to match the pension base of 112 billion euros. ${ }^{7}$ We assume that the initial funding ratio is $F_{0}=100 \%$, the wage growth factor is $\pi=1 \%$ and population growth is $g=0 \% .^{8}$ The career development is $c^{H}=c^{L}=0.5 \%$ under our benchmark parameter setting. Finally, we assume that the discount rate for determining the price of pension accrual is actuarially fair, i.e. $Q=\frac{1}{1+z}=1$. Table 3 provides an overview of the parameter settings.

\footnotetext{
6 The weighted average of the accrual rates of Dutch pension funds in 2016 equals $1.829 \%$.

7 According to the DNB E-line annual reports 2016 for Dutch pension funds the pension base is 112 billion euros. Including Dutch collective pension arrangements with insurance companies which also apply a UPPS would increase the pension base to 126 billion euros. The Dutch GDP over 2016 is about 700 billion euros (CBS 2017).

${ }^{8}$ Labor supply projections indicate a growth rate close to zero (de Euwals et al. 2014).
} 
Table 3 Parameter settings

\begin{tabular}{lllll}
\hline Description & Symbol & Set 1 & Set 2 & Set 3 \\
\hline Working cohorts & $n$ & 40 & 40 & 40 \\
Retired cohorts & $m$ & 20 & 20 & 20 \\
Interest rate & $r$ & $1 \%$ & $\mathbf{1 . 5 \%}$ & $1 \%$ \\
Indexation rate & $z$ & $0 \%$ & $0 \%$ & $0 \%$ \\
Wage inflation & $\pi$ & $0.5 \%$ & $\mathbf{1 \%}$ & $0.5 \%$ \\
Population growth & $g$ & $0 \%$ & $0 \%$ & $0 \%$ \\
Fraction population type $H$ & $\alpha$ & $100 \%$ & $100 \%$ & $\mathbf{5 0 \%}$ \\
Career development type $H$ & $c^{H}$ & $0.5 \%$ & $0.5 \%$ & $\mathbf{1 \%}$ \\
Career development type $L$ & $c^{L}$ & $0.5 \%$ & $0.5 \%$ & $\mathbf{0 \%}$ \\
Pension base (in billion euros) & $P B_{t}$ & 112 & 112 & 112 \\
Accrual rate & $\rho$ & $1.829 \%$ & $1.829 \%$ & $1.829 \%$ \\
Transition effect (in billion euros) & & 36.90 & 47.99 & 36.93 \\
\hline
\end{tabular}

The bold values are the ones that are different with respect to Set 1

\subsection{Transition Effects of Abolishing the UPPS}

Similar to the figures and table in Sect. 3, Figs. 5, 6 and Table 4 show the net value losses and gains for the various generations. The numbers are generated based on the parameter Set 1 from Table 3, where we have 60 overlapping generations. Note that the shapes of the graphs are quite similar to the ones in Sect. 3 with only three overlapping generations.

The top graph in Fig. 5 shows that the contribution rate decreases with age. The bottom indicates the total net value losses of the unfortunate generations, which are the generations who have a negative net value transfer from abolishing the UPPS. This total net value losse are largest at an interest rate of $2.4 \%$ and lowest for an interest rate of zero or infinity.

Both Fig. 6 and Table 4 show that net value transfer of the youngest generation is zero for two special cases. First, this holds for an interest rate of zero, because that implies that the value of the contributions and benefits are equal with and without the UPPS. Second, there is no net value transfer for the youngest generation when the Aaron condition holds with equality, which is the case here for an interest rate equal to the wage growth rate $(r=\pi)$.

Figure 7 shows the net value transfer per cohort as a function of age corresponding to parameter Set 1 . The age of 0 represents a generation which enters the labor market next year. Negative values for age represent future generations. The sum of all net value transfers equals zero. This indicates that abolishing the UPPS is indeed a zero-sum game.

Figure 7 shows that most currently working cohorts lose value by abolishing the UPPS, while future cohorts and some of the youngest currently working cohorts benefit because they escape financing the implicit PAYG element debt. We define the sum of the net value losses as the transition effect. The last row 


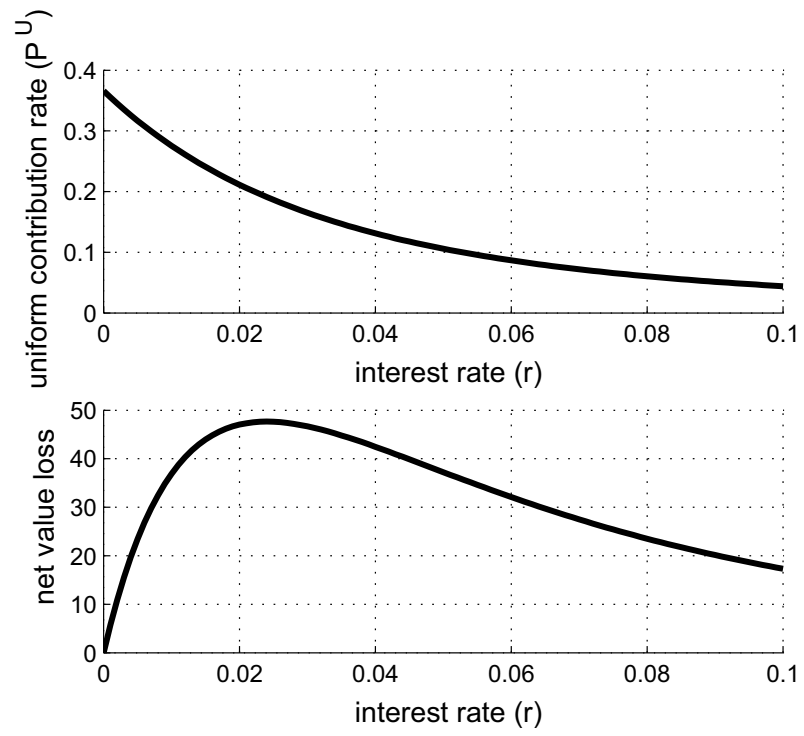

Fig. 5 The contribution rate and the net value loss in billion euros for unfortunate generations as a function of the interest rate-Table 3 Set 1 provides the underlying parameter assumptions

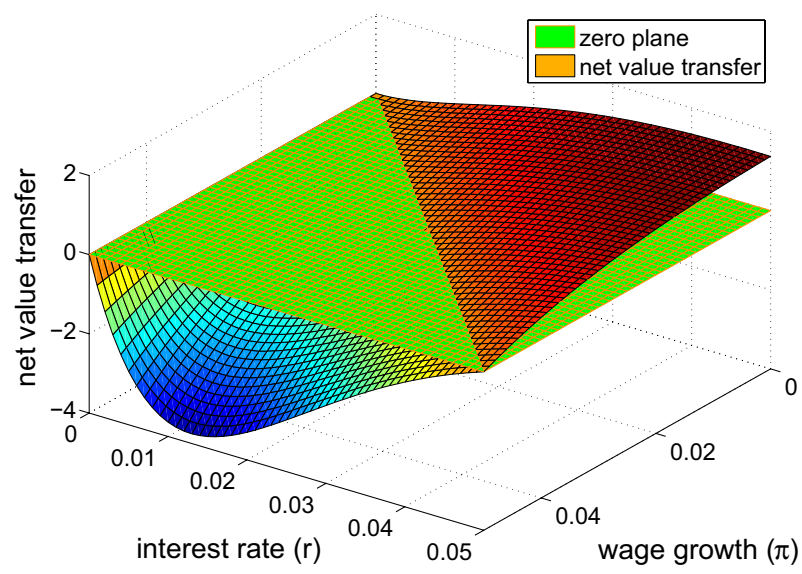

Fig. 6 Net value transfer of the youngest generation in billion euros as a function of the interest rate $(r)$ and wage growth $(\pi)$-Table 3 Set 1 provides the underlying parameter assumptions

of Table 3 indicates the transition effects for three different parameter settings, which result in estimates ranging from 37 and 48 billion euros, i.e. 5-7\% of the Dutch GDP. 
Table 4 Net value transfer of the youngest generation in billion euros as function of the interest rate $(r)$ and wage growth $(\pi)$-Table 3 Set 1 provides the underlying parameter assumptions

\begin{tabular}{lllll}
\hline $\begin{array}{l}\text { Net value transfer } \\
\text { youngest generation }\end{array}$ & $\pi=0.00$ & $\pi=0.01$ & $\pi=0.02$ & $\pi=0.05$ \\
\hline$r=0.00$ & 0 & 0 & 0 & 0 \\
$r=0.01$ & 0.332 & 0 & -0.489 & -3.639 \\
$r=0.02$ & 0.824 & 0.496 & 0 & -3.303 \\
$r=0.05$ & 1.369 & 1.297 & 1.160 & 0 \\
\hline
\end{tabular}

Fig. 7 Net value transfer per cohort in billion euros as a function of age-Table 3 Set 1 provides the underlying parameter assumptions. Note that in this model we give an alternative interpretation to age: the employees have the age of 1-40 and retirement starts at the age of 41. A more realistic interpretation is simply obtained by adding 25 years to these ages

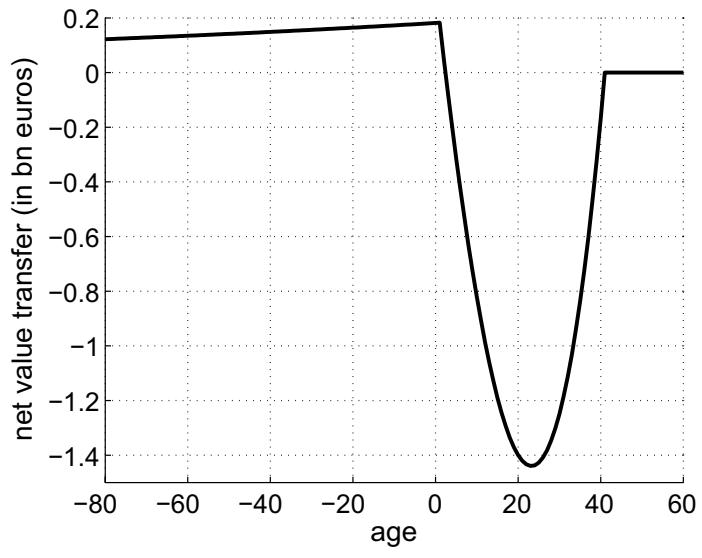

\subsection{Wage Growth}

So far, we considered a demography and wage profile with constant growth rate and a certain age of death. This way, we could better compare the analytical results from the 3-OLG model to the results from the multi-OLG model. In order to improve the accuracy of the estimates, we extent the model with a more realistic age profile and distribution of the population.

Deelen (2012) shows that wage has a quadratic relation towards tenure. In line with his results we now apply the following model for career development:

$$
f^{i}(s)=b_{0}+s b_{1}+s^{2} b_{2}, i \in\{H, L\} .
$$

Hence, the wage for a participant with type $i$ and age $s$ at time $t$ equals $w_{s, t}^{i}=f^{i}(s)(1+\pi)^{t}$.

If we do not distinguish between types, i.e. $\alpha=1$, then using data on the aggregate wage profile for the Dutch labor market over 2014 (CBS 2017) we estimate the following coefficients: 


$$
\begin{aligned}
& \hat{b}_{0}=19.380, \\
& \hat{b}_{1}=2.501, \\
& \hat{b}_{2}=-0.052 .
\end{aligned}
$$

From the forecast table of the Dutch Actuarial Society (Actuarieel Genootschap 2014) we determine the mortality rates of someone with real age of 55 in 2017 , where we take the average of men and women. Similarly we use the mortality rates to obtain an age distribution for the entire population. The annuity factors of the vector $K$ now become

$$
K_{i}=\sum_{j=\max (n+1-i, 0)}^{T-i} \frac{p_{i+j}}{p_{i}} q^{j},
$$

where $p_{i}$ is the probability that someone with real age of 25 year becomes at least $25+i$. The parameter $T$ is the final age, which we set equal to 100 , i.e. nobody gets older than 125 year in terms of real age. ${ }^{9}$ By taking the mortality rates into account, we effectively incorporate a larger discount for determining the annuity factors.

The working population and the pension base as a function of age are shown in Fig. 8. The pension base is obtained by deducting the franchise of 13,000 euros from the gross wage. ${ }^{10}$ Close to retirement less people have a full-time job, which reduces the pension base further. Modeling this income distribution, this demography and and the parameter settings of Set 1 and Set 2 from Table 3 result in a transition effect of, respectively, $\mathbf{3 6 . 7 2}$ and $\mathbf{4 4 . 5 0}$ billion euros.

Figure 9 shows the net value transfer under the more realistic working population and pension base. This time, the vertical axis presents the net value transfer per cohort in terms of percentage change of the total pension value. Figure 9 shows that this net value transfer of a future generation is $+0.63 \%$, while the maximum loss $(-4.98 \%)$ is obtained by the cohort which is currently 24 years old (i.e. real age 49). Hence, the net value transfers are within the range of $\pm 5 \%$ of total pension value for each cohort.

\subsection{Sensitivity Analysis}

We again take Set 1 from Table 3 for the benchmark parameter settings. We do not apply the parameters $c^{H}$ and $c^{L}$ yet, using instead the aggregate working population and pension base we described in Sect. 4.3. For the sensitivity analysis we vary one parameter at the time and show the corresponding changes in the transition effect in Fig. 10. From these graphs we can conclude that the transition effect is quite sensitive to several parameter assumptions. The transition effect is largest for an interest

\footnotetext{
9 Since $p_{i}<0.1 \%, \forall i \geq 83$, the probability that somebody with real age of 25 becomes at least $25+83=108$ years old in terms of real age is less than $0.1 \%$. Hence, the results are not affected by choosing a larger value for the parameter $T$.

10 The franchise is the level of income over which no pension is accrued in the second pillar since it is covered under the national first pillar PAYG system (the "AOW").
} 
Fig. 8 Pension base over life and working population. Note that in this model we give an alternative interpretation to age: the employees have the age of $1-40$ and retirement starts at the age of 41. A more realistic interpretation is simply obtained by adding 25 years to these ages
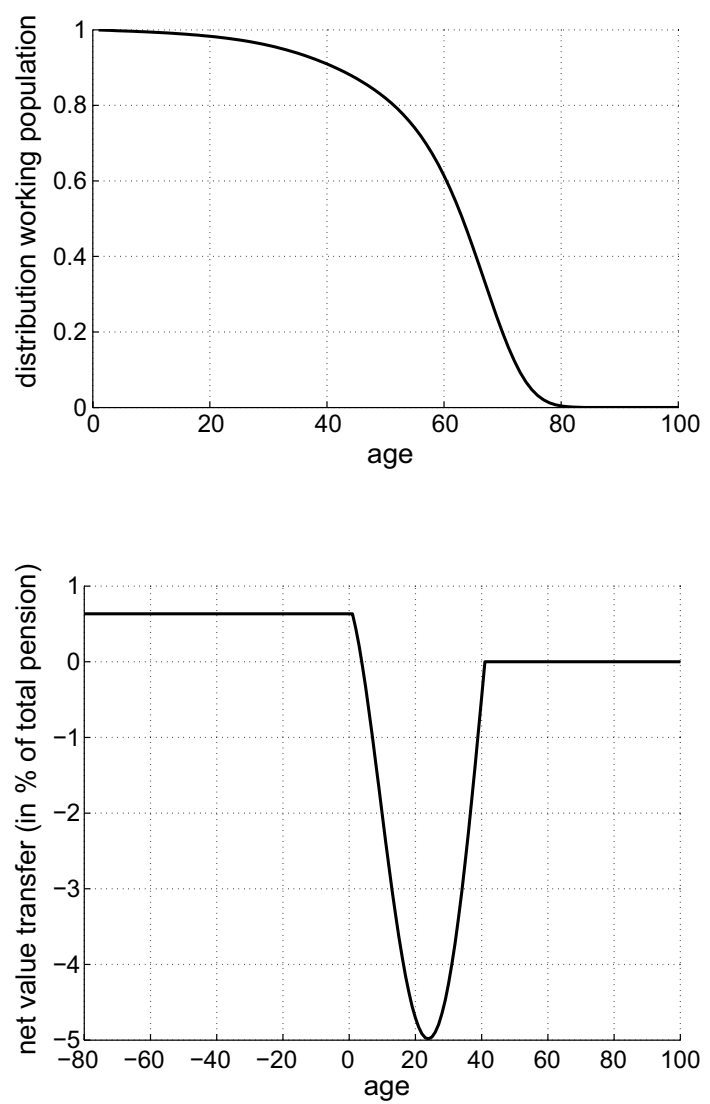

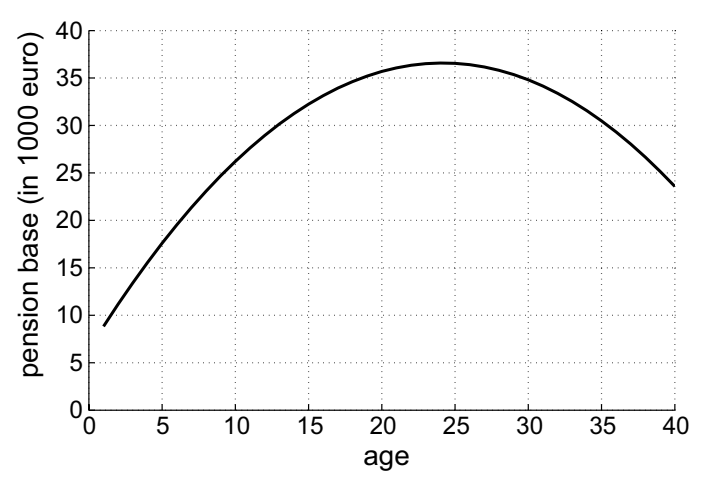

Fig. 9 Net value transfer per cohort as percentage of total pension value as a function of age - see Table 3 Set 1 for the underlying parameter settings and Sect. 4.3 for the underlying working population and pension base over life. Note that in this model we give an alternative interpretation to age: the employees have the age of 1-40 and retirement starts at the age of 41. A more realistic interpretation is simply obtained by adding 25 years to these ages

rate around $2.1 \%$. For lower interest rates, the transition effect is increasing with the interest rate, while for larger interest rates $(r>2.1 \%)$ the transition effect decreases with $r$. The reason is that for high interest rates, the uniform and the actuarially fair contribution rates decrease towards zero and, hence, the differences decrease as well.

If we compare Set 1 and Set 2 of Table 3, it shows that the transition effect increases by 8 billion euros, from 37 billion to 45 billion, if interest rates rise from 

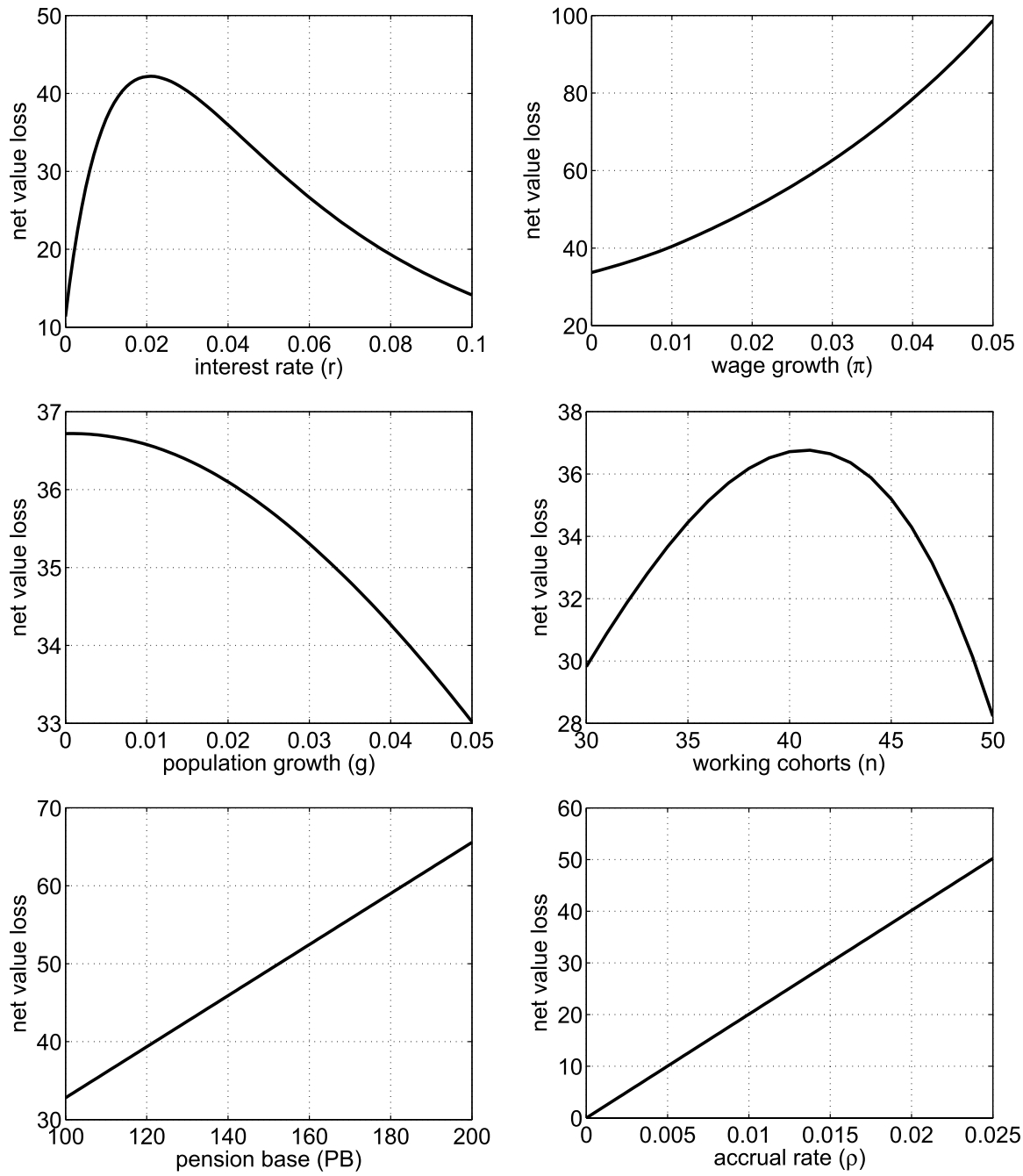

Fig. 10 Sensitivity analysis of the transition effect in billion euros

1 to $1.5 \%$. If the transition effect is recalculated, but now based on an assumption of an interest rate of $0 \%$ in line with the swap curve at the end of July 2019, then the transition effect falls to 11 billion euros-see the top left panel of Fig. 10. Hence, in 
contrast to previous calculation, the transition effect is no longer zero at $r=0$. The reason is that we now incorporate mortality rates, which also introduces discounting when determining the annuity factors, as explained in Sect. 4.3. Only if the probability of surviving until retirement is $100 \%$, then the transition effect becomes zero at an interest rate of zero $(r=0)$.

Wage growth increases the transition effect, while the net value loss of abolishing the UPPS is lower with high population growth. The number of years working increases the transition effect for low $n$, because the difference between the actuarially fair contribution rates and the uniform contribution rate become larger with more working years. However, for large $n$, people have a short retirement period, as mortality rates remain equal, such that the number of working years decrease the transition effect. The latter effect dominates at $n \geq 42$ (i.e. real age 67). The pension base and the accrual rate are both directly proportional to the transition effect.

Figure 10 shows that the transition effect strongly depends on the parameter settings chosen. Lever et al. (2017) present a transition effect of 55 billion euros. There are several explanations for this difference. Here we discuss the four main differences in parameter and modeling assumptions. First, we do not model the survivor's pension, as the UPPS does not fully apply to this pension in the Netherlands, while Lever et al. (2017) assume a top-up of $0.25 \%$-point for the accrual rate to compensate for the survivor's pension. Second, we apply a pension base of 112 billion euros for pension funds, while Lever et al. (2017) take 160 billion euros; their number is higher because they include pension arrangements with insurance companies and because they assume a total pension base growth between 2016-2020 of 13.6\%. We use 2016 as a base year and we exclude insurance companies from our analysis since the UPPS typcially does not apply to insurance company based pensions. Third, Lever et al. (2017) apply a yield curve which increases up to almost $1.5 \%$ for long maturities, while we simplify the analysis by taking a flat yield curve which equals $1 \%$. Fourth, the outcomes of Lever et al. (2017) are based on a stochastic approach, which also takes pension cuts and indexation of pension rights into account, while we apply a deterministic setting with nominal (guaranteed) pension rights. The first and the second difference in assumptions, i.e. the larger accrual rate and pension base, result in a larger transition effect. It is not a priori obvious whether the difference in yield curve increases or decreases the transition effect, because our flat $1 \%$ interest rate overestimates the short run interest rate and underestimates the long run intereste rate. The stochastic analysis most likely results in a lower transition effect as, in the Netherlands, the pension cuts in response to low funding ratios are in principle unlimited while adjustments upwards (once funding ratios are high) are limited to what is necessary for indexation to the wage- or price inflation. This would imply lower results under a stochastic estimation.

\subsection{Contribution Rate Reduction}

As described earlier, future generations need to pay a lower contribution rate in order to obtain the same level of pension benefits when the UPPS is abolished, as people do not have to pay for the implicit debt anymore. Similarly, the future generations 
Fig. 11 Reduction of the contribution rate in percentage points after abolishing UPPS for different interest rates-see Table 3 Set 1 for the underlying parameter settings and Sect. 4.3 for the underlying working population and pension base over life

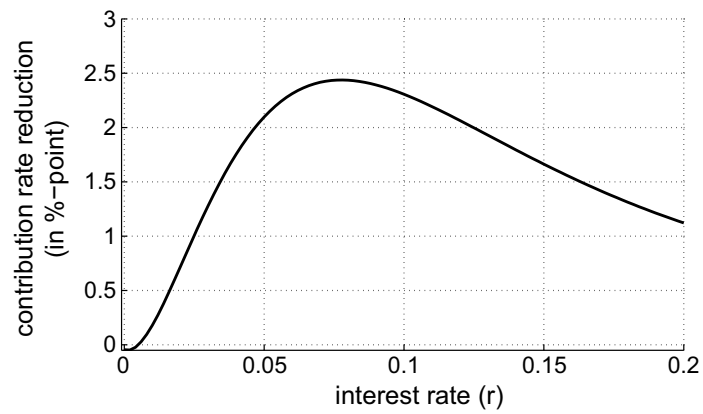

could also pay the same contribution rate in order to obtain a higher level of pension benefits. This would be equivalent in terms of economic value.

Suppose the UPPS is abolished by switching to a system with a uniform contribution rate and accrual rates which are descending with age, as illustrated in Fig. 1a. Then we obtain for the benchmark parameter setting $(r=0.01)$ a contribution rate reduction of $28.41-28.23 \%$, so a reduction of 0.18 percentage point. ${ }^{11}$ For larger interest rates, the contribution rate reduction increases, see Fig. 11, as the Aaron condition holds more strongly, while for interest rates around zero, the reduction is negative, as the Aaron condition does not hold anymore. Similarly to Fig. 2, we have that the effects converge to zero when the interest rate becomes extremely large, as the contribution rates converge to zero as well.

\subsection{The Subsidy from Low to High Skilled Workers}

So far we did not distinguish between participants with a flat wage profile and participants with a steep wage profile in this section, which we refer to as the low skilled and high skilled workers, respectively. To make that distinction we use the wage profiles for $f^{H}(s)$ and $f^{L}(s)$ using data of wages in the Netherlands from CBS (2017). Table 5 shows the estimated coefficients for $\alpha=1, \alpha=0.35$ and $\alpha=0.1$. The pension base profiles are shown in Fig. 12. These are the gross wages after deducting the franchise. Moreover, note in the right panel of Fig. 12 that we limit the pension base to 100,000 euros minus the franchise for the high skilled workers, as this is nowadays the fiscal maximum for pension accrual in the Netherlands.

The columns under $\alpha=1$ in Table 5 are a repetition of the results obtained in Sect. 4.3. This table also provides the results when making the distinction between wage profiles. Empirically, we find that when we take the wage profile of the $10 \%$ wealthiest participants (i.e. $\alpha=0.1$ ), the differences in wage profile are larger between low skilled workers and high skilled workers than what we get when we take the wealthiest $35 \%$ of the population (i.e. $\alpha=0.35$ ). When taking

\footnotetext{
11 The pension base is 112 billion euros, so in the year of abolishing the UPPS this is a reduction of total contributions equal to 0.2 billion euros $(\approx 112 * 0.18 \%)$.
} 
Table 5 Estimated coefficients for several wage profiles—-see Table 3 Set 1 for the underlying benchmark parameter settings

\begin{tabular}{|c|c|c|c|c|c|c|}
\hline \multirow{2}{*}{$\begin{array}{l}\text { Fraction type } H \\
\text { Type }\end{array}$} & \multicolumn{2}{|l|}{$\alpha=1$} & \multicolumn{2}{|l|}{$\alpha=0.35$} & \multicolumn{2}{|l|}{$\alpha=0.1$} \\
\hline & $L$ & $H$ & $L$ & $H$ & $L$ & $H$ \\
\hline$\hat{b}_{0}$ & - & 19.378 & 10.935 & 35.609 & 15.776 & 50.440 \\
\hline$\hat{b}_{1}$ & - & 2.501 & 1.628 & 4.021 & 2.100 & 6.172 \\
\hline$\hat{b}_{2}$ & - & -0.052 & -0.037 & -0.078 & -0.044 & -0.089 \\
\hline \multicolumn{7}{|l|}{ Transition effect (in bn euros) } \\
\hline Total & 36.72 & & 37.02 & & 37.67 & \\
\hline Per type & - & 36.72 & 6.48 & 30.54 & 11.73 & 25.94 \\
\hline Per $1 \%$ population & - & 0.3672 & 0.0997 & 0.8727 & 0.2882 & 1.1734 \\
\hline Perverse subsidy (in bn euros) & - & - & -10.06 & 10.06 & -10.73 & 10.73 \\
\hline
\end{tabular}

Fig. 12 Pension base as a function of age for low and high skilled participants. In the upper (lower) panel the fraction of high skilled participants is $35 \%$ $(10 \%)$. Note that in this model we give an alternative interpretation to age: the employees have the age of 1-40 and retirement starts at the age of 41 . A more realistic interpretation is simply obtained by adding 25 years to these ages
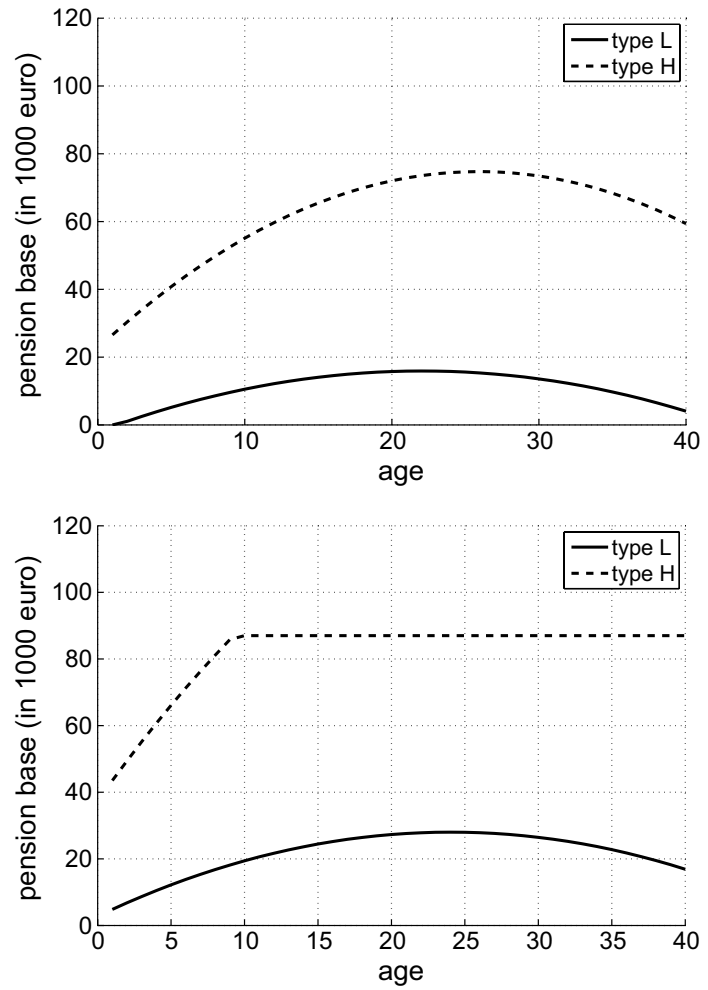

into account that the wealthy group has a steeper wage profile, the aggregate transition effect remains about 37 billion: the perverse subsidy mechanism redistributes but does not lead to any significant change in the overall size of the transition effect. 
With a steeper wage profile, old participants gain more from the subsidies from young to old under the UPPS. Hence, the transition effect is larger for high skilled participants. The second-to-last row of Table 5 shows that the transition effect of a participant with a steep wage profile (type $H$ ) is indeed substantially larger than for a participant with a flat wage profile (type $L$ ). The low skilled group has a relatively flat wage profile and, therefore, a lower transition effect. On the other hand, high skilled participants typically paid more subsidy to old cohorts when they were young themselves under the UPPS.

The uniform contribution rate is the same for all participants, independent of age or type. As we did before, we can alternatively differentiate between type, by considering a uniform contribution rate for low and high skilled workers separately:

$$
P^{U, k}=\frac{\rho \sum_{i=1}^{n}\left(u_{i, t}^{k} w_{i, t}^{k} K_{i}\right)}{\sum_{i=1}^{n}\left(u_{i, t}^{k} w_{i, t}^{k}\right)} .
$$

This way, the contribution rate remains independent of age. This alternative system is more favorable to the low skilled participants, since there is no perverse subsidy. We can compare the UPPS with this alternative system in order to quantify the perverse subsidy under the UPPS. That procedure leads to estimates of total perverse subsidies for $\alpha=0.35$ and $\alpha=0.1$ of, respectively, 10.06 and 10.73 billion euros (see the last row of Table 5).

These results indicate that there are substantial value transfers under the UPPS from participants with a flat wage profile to participants with a steep wage profile, which could in itself already be a reason to abolish the UPPS and switch to an actuarially fair system. Moreover, this perverse subsidy in the UPPS can arguably be construed as an argument for not fully compensating for all the negative transition effects that are triggered by abolishing the UPPS.

\subsection{No Inflow of New Participants}

So far we assumed continuous inflow and outflow of participating cohorts. However, some pension funds are closed for new inflow of participants. In such a setting the current youngest generation will remain the youngest generation and, therefore, this generation will always pay subsidies to older generations under the UPPS. However, these subsidies reduce over time.

Here we explain this feature in more detail. At time $t=0$, the youngest generation pays a subsidy, similar to the setting with continues inflow. At time $t=1$, there are no longer $n$ working cohorts, but $n-1$, because there is no new inflow. Particularly, at time $t=n-2$, there are only two working generations left in the pension fund, where the youngest generation pays a strictly positive subsidy if $q<1$ (see "Closed Pension Fund with Two Remaining Working Generations" in Appendix). With $Q=1, z=0$ and strictly positive interest rates, the condition $q=\frac{1}{1+r}<1$ is clearly satisfied. In other words, even when this generation is only 


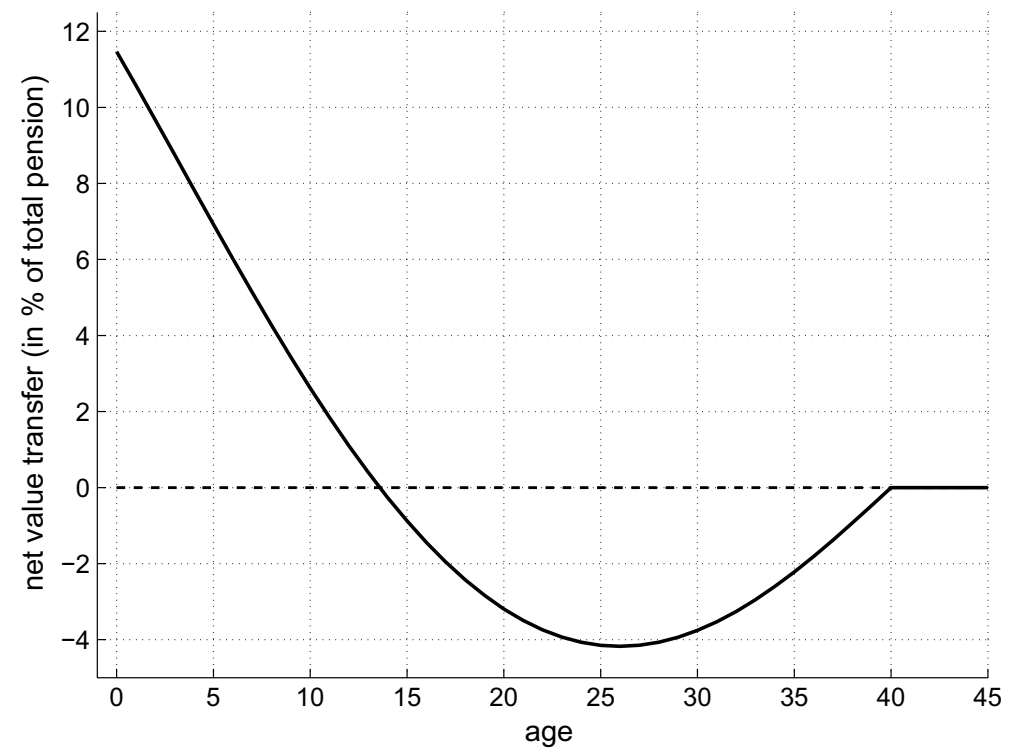

Fig. 13 Net value transfer per cohort as percentage of total pension value as a function of age for a closed pension fund-see Table 3 Set 1 for the underlying parameter settings and Sect. 4.3 for the underlying working population and pension base over life. Note that in this model we give an alternative interpretation to age: the employees have the age of 1-40 and retirement starts at the age of 41 . A more realistic interpretation is simply obtained by adding 25 years to these ages

2 years away from retirement, it still does not receive any subsidy, but pays a subsidy to the cohort which is one year older.

At time $t=n-1$, this generation is the only working generation left in the pension fund. In that case, the uniform contribution rate is similar to the actuarially fair contribution rate and no subsidy is transferred as we have $P^{U}=\rho K_{n}=P_{n}$.

In Fig. 13 we show the net value transfers expressed in percentage of total pension value for the different age cohorts when the pension fund is closed for new generations. Previously, we have seen that the maximum loss of $4.98 \%$ is obtained at the cohort working 24 years, while under the closed pension fund setting the maximum loss reduces to $4.18 \%$ for the cohort working 26 years. The maximum gain, however, increases substantially for the youngest age cohort. As this cohort always pays subsidies under the UPPS and never receives these subsidies, the gain of abolishing UPPS increases to $11.47 \%$, instead of the previously obtained value of $0.63 \%$.

This result indicates that pension funds applying UPPS in practice negatively affects the pension of young cohorts when the inflow of new generations is nil or limited. Moreover, this result indicates that the gains from abolishing UPPS for young generations are substantially overestimated when assuming it should be estimated in a setting with current participating generations only. 


\subsection{Actuarial Fairness}

In our analysis we have not considered any adjustments of the pension benefits or pension contributions in case funding ratios strongly deviating from $100 \%$. To some extent that is an unrealistic assumption, because it is unlikely that with high funding ratios the participants of the fund would not receive any compensation from a high buffer through a lower contribution rate or an upside adjustment of their pension rights. Similarly funding ratios substantially below $100 \%$ will typically lead to regulatory intervention and mandated recovery actions to enhance the solvency of the pension fund.

Even though we have not considered any policy actions to stabilise the funding ratio, we observe in Fig. 14a that over a 50 year horizon the funding ratio only moves a few percentage points when the initial funding ratio is not far from $100 \%$. These funding ratio trajectories are plotted with the underlying working population and pension base over life as described in Sect. 4.3 and the parameter settings from Table 3 Set 1. Hence, we again assumed that the parameter $Q=1$, implying that the price of pension accrual is actuarially fair. Figure $14 \mathrm{~b}$ also considers the funding ratio trajectories for different values of $Q$. Suppose for example that we have $Q<1$, so $q<\frac{1+z}{1+r}$, then the price for pension accrual is less than what would be actuarially fair. Figure $14 \mathrm{~b}$ shows that participants paying an actuarially unfair price for pension accrual has a substantial impact on the funding ratio development. With $0.5 \%$-point reduction in price, i.e. $Q=99.5 \%$, the funding ratio already decreases from 100 to $90 \%$ in about 20 years. From these graphs we can conclude that deviating from actuarially fairness can have a substantial impact on the solvency of the pension fund in the long run and, therefore, is unlikely to be maintained.

\section{Conclusion}

Abolishing the UPPS will cause most current working cohorts to miss out on subsidies they were entitled to since they have paid similar subsidies to old cohorts in their earlier working years. However, some young generations and all future generations benefit from abolishing the UPPS due to contribution reduction. This paper shows the net value transfers for different generations and for different parameter assumptions. We refer to the transition effect as the total transfer loss of generations by abolishing the UPPS. From our benchmark estimate we obtain a transition effect of about 37 billion euros at an interest rate of $1 \%$ and about 11 billion euros at an interest rate of $0 \%$. However, arguably more important than this aggregate number is our conclusion that for each cohort the transition effect as a percentage of their pension value lies within the range of $\pm 5 \%$. We show that the transition effect is directly proportional to both the pension base and the accrual rate; higher wage growth increases the transition effect, while (labor) population growth decreases the transition effect. The transition effect is largest for an interest rate slightly above $2 \%$. Below this limit, the transition effect strongly increases with the interest rate, while for higher interest rates the transition effect gradually and slowly decreases with the interest rate. The reason is that for high interest rates, the uniform and the actuarially 
Fig. 14 Funding ratio development over time for different starting funding ratios and different parameter value $Q$ for actuarially fairness

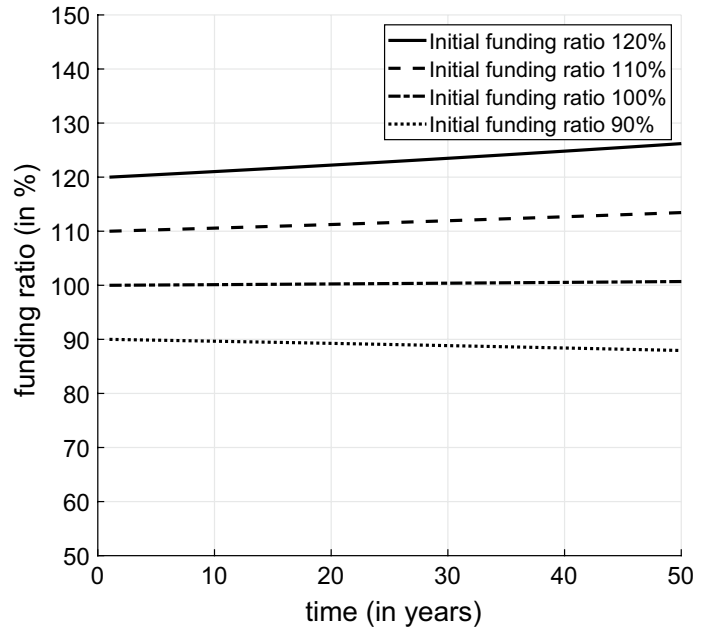

(a) Parameter $Q=1$

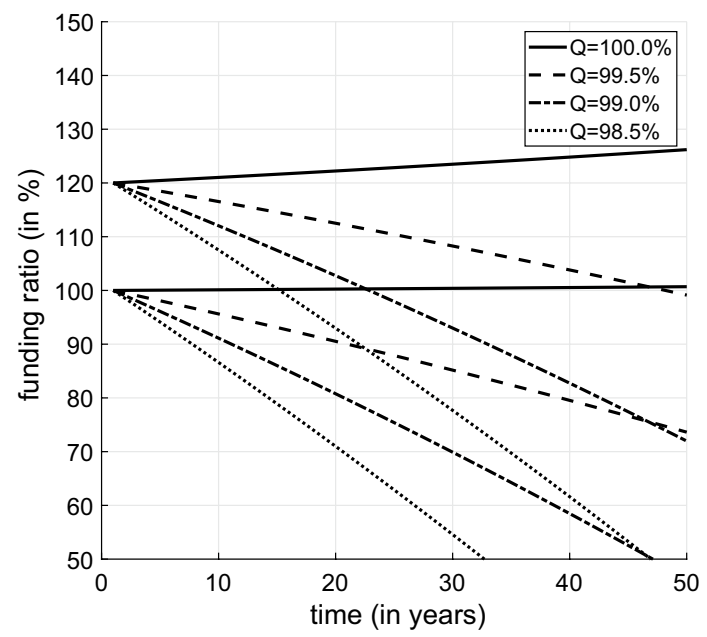

(b) Initial funding ratio $F_{0}=100 \%$ and $F_{0}=120 \%$

fair contribution rates decrease towards zero and, hence, the differences between then decrease to zero as well. Finally, we have shown that there are substantial value transfers from low to high skilled participants under the UPPS, which in practice means a transfer from low-income to high-income workers, from poor to rich. This is in itself already a strong reason for abolishing the UPPS. The total perverse subsidy from participants with a flat wage profile to participants with a steep wage profile embedded in the current Dutch second pillar pension system is about 10 billion euros, which is about $1.5 \%$ of the Dutch GDP. This value transfer will continue when the UPPS is not abolished. The fact that the current system embeds a subsidy from participants with a flat wage profile to participants with a steep wage profile, in 
practice from poor to rich workers, is arguably a reason for not (fully) compensating for the transition effect upon abolishing the UPPS.

The analysis in this paper can usefully be extended into several directions. First, we apply a deterministic model, but using a stochastic model would allow for the conditional indexation of pension rights and the probability of cutting pensions in calculating the transition effect, although we do not expect the results to change significantly if we would use a stochastic model. Moreover, we hope to have demosntrated that the economic intuition behind the transition effects becomes clearer when the analysis focuses on abolishing the UPPS only and does not take into account the cross-effects with other (country) specific pension policies. Second, we assume that the term structure is flat, but in reality there is a yield curve, which means that a different discount rate should be used for different maturities. Finally, the estimation for the perverse subsidy from low to high skilled workers, which in practice corresponds to a transfer from low- to high-income workers can be improved in two ways. First the social economic differences between participants within one pension fund are in practice smaller than differences between all participants in the system as a whole. For example, some pension funds have participants from one type of profession only and average life-expectancy certainly varies across professional groups. By modeling one pension fund with participants equal to the total labor force, i.e. with both low and high skilled participants, the perverse subsidy is possibly overestimated. But against that is a second distributional effect, one that is likely to be of more quantitative significance, low skilled workers have a much lower life expectancy than high skilled workers. Not taking into account differences in life expectancy between wage groups leads one to underestimate the perverse subsidy within the UPPS.

Open Access This article is licensed under a Creative Commons Attribution 4.0 International License, which permits use, sharing, adaptation, distribution and reproduction in any medium or format, as long as you give appropriate credit to the original author(s) and the source, provide a link to the Creative Commons licence, and indicate if changes were made. The images or other third party material in this article are included in the article's Creative Commons licence, unless indicated otherwise in a credit line to the material. If material is not included in the article's Creative Commons licence and your intended use is not permitted by statutory regulation or exceeds the permitted use, you will need to obtain permission directly from the copyright holder. To view a copy of this licence, visit http://creativecommons.org/licen ses/by/4.0/.

\section{Appendix: Mathematical Derivations}

\section{Liabilities in Recursive Form}

The liabilities can be written in recursive form as follows 


$$
\begin{aligned}
L_{t+1} & =\sum_{i=1}^{n+m} K_{i}\left(u_{i, t+1}^{H} B_{i, t+1}^{H}+u_{i, t+1}^{L} B_{i, t+1}^{L}\right) \\
& =(1+g) \sum_{i=1}^{n+m} K_{i}\left(u_{i, t}^{H} B_{i, t+1}^{H}+u_{i, t}^{L} B_{i, t+1}^{L}\right) \\
& =(1+g)(1+\pi) \sum_{i=1}^{n+m} K_{i}\left(u_{i, t}^{H} B_{i, t}^{H}+u_{i, t}^{L} B_{i, t}^{L}\right) \\
& =(1+g)(1+\pi) L_{t} .
\end{aligned}
$$

This analytical expression only holds since we have a constant inflow and outflow of participants, such that new accrual cancels out against payed out benefits.

\section{Net Value Transfer}

The pension base can be rewritten as follows:

$$
\begin{aligned}
P B_{t}= & \sum_{i=1}^{n}\left(u_{i, t}^{H} w_{i, t}^{H}+u_{i, t}^{L} w_{i, t}^{L}\right) \\
= & (1+\pi)^{t}(1+g)^{t} \sum_{i=1}^{n}\left(u_{i, 0}^{H} w_{i, 0}^{H}+u_{i, 0}^{L} w_{i, 0}^{L}\right) \\
= & (1+\pi)^{t}(1+g)^{n+t} \sum_{i=1}^{n}\left[\alpha(1+g)^{-i} w_{i, 0}^{H}+(1-\alpha)(1+g)^{-i} w_{i, 0}^{L}\right] \\
= & (1+\pi)^{t}(1+g)^{n+t} \sum_{i=1}^{n}\left[\alpha(1+g)^{-i}\left(1+c^{H}\right)^{i-1}\right. \\
& \left.+(1-\alpha)(1+g)^{-i}\left(1+c^{L}\right)^{i-1}\right] \\
= & (1+\pi)^{t}(1+g)^{n-1+t} \sum_{i=0}^{n-1}\left[\frac{\alpha\left(1+c^{H}\right)^{i}+(1-\alpha)\left(1+c^{L}\right)^{i}}{(1+g)^{i}}\right] \\
= & (1+\pi)^{t}(1+g)^{n-1+t} \sum_{i=0}^{n-1} \frac{\chi_{i}}{(1+g)^{i}} \\
\text { with } \chi_{i}= & \alpha\left(1+c^{H}\right)^{i}+(1-\alpha)\left(1+c^{L}\right)^{i}
\end{aligned}
$$

and, hence, the uniform contribution rate can be rewritten as 


$$
\begin{aligned}
P^{U} & =\frac{\rho \sum_{i=1}^{n}\left(u_{i, t}^{H} w_{i, t}^{H}+u_{i, t}^{L} w_{i, t}^{L}\right) K_{i}}{P B_{t}} \\
& =\frac{\rho \sum_{i=1}^{n}\left(u_{i, t}^{H} w_{i, t}^{H}+u_{i, t}^{L} w_{i, t}^{L}\right) K_{i}}{\sum_{i=1}^{n}\left(u_{i, t}^{H} w_{i, t}^{H}+u_{i, t}^{L} w_{i, t}^{L}\right)} \\
& =\rho q^{n+1} \frac{(1+\pi)^{t}(1+g)^{t} \sum_{i=0}^{m-1} q^{i} \sum_{i=1}^{n}\left[q^{-i}\left(u_{i, 0}^{H} w_{i, 0}^{H}+u_{i, 0}^{L} w_{i, 0}^{L}\right)\right]}{(1+\pi)^{t}(1+g)^{n-1+t} \sum_{i=0}^{n-1} \frac{\chi_{i}}{(1+g)^{i}}} \\
& =\rho q^{n} \frac{\sum_{i=0}^{m-1} q^{i} \sum_{i=0}^{n-1} \frac{\chi_{i}}{q^{i}(1+g)^{i}}}{\sum_{i=0}^{n-1} \frac{\chi_{i}}{(1+g)^{i}}} .
\end{aligned}
$$

Then, the net value transfer of a group of generation $j$ with type $k$ is equal to

$$
\begin{aligned}
N V T_{j, t}^{k} & =u_{j, t}^{k} \sum_{i=\max (j, 1)}^{n} \frac{w_{i, t+i-j}^{k}\left(P^{U}-P_{i}\right)}{(1+r)^{i-j}} \\
& =\frac{(1+g)^{t-j+n}(1+\pi)^{t-j+1}}{(1+r)^{1-j}} u_{n, 0}^{k} w_{1,0}^{k} \sum_{i=\max (j, 1)}^{n}\left(\frac{(1+\pi)\left(1+c^{k}\right)}{(1+r)}\right)^{i-1}\left(P^{U}-P_{i}\right) \\
& =\Xi_{j, t} u_{n, 0}^{k} \sum_{i=\max (j-1,0)}^{n-1}\left(\frac{(1+\pi)\left(1+c^{k}\right)}{q(1+r)}\right)^{i}\left(q^{i} \frac{\sum_{l=0}^{n-1} \frac{\chi_{l}}{q^{l}(1+g)}}{\sum_{l=0}^{n-1} \frac{\chi_{l}}{(1+g)^{l}}}-1\right) \\
\text { with } \Xi_{j, t} & =\rho\left(\frac{(1+g)(1+\pi)}{(1+r)}\right)^{1-j}(1+\pi)^{t}(1+g)^{t+n-1}[=n] m+n-1 \sum q^{l} .
\end{aligned}
$$

For the entire generation, the net value transfer is equal to

$$
\begin{aligned}
N V T_{j, t} & =N V T_{j, t}^{H}+N V T_{j, t}^{L} \\
& =\Xi_{j, t} \sum_{i=\max (j-1,0)}^{n-1} \chi_{i}\left(\frac{(1+\pi)}{q(1+r)}\right)^{i}\left(q^{i} \frac{\sum_{l=0}^{n-1} \frac{\chi_{l}}{q^{l}(1+g)^{l}}}{\sum_{l=0}^{n-1} \frac{\chi_{l}}{(1+g)^{l}}}-1\right) .
\end{aligned}
$$

\section{Subsidy from Low to High Skilled Participants in 3-OLG Model}

The uniform contribution rate for the low type minus the original uniform contribution is 


$$
\begin{aligned}
P^{U, L}-P^{U} & =\rho q\left[\frac{(1+g) q+\left(1+c^{L}\right)}{(1+g)+\left(1+c^{L}\right)}-\frac{(1+g) q+\chi_{1}}{1+g+\chi_{1}}\right] \\
& =\rho q\left[\frac{(1+g) q+\left(1+c^{L}\right)}{(1+g)+\left(1+c^{L}\right)}-\frac{(1+g) q+\left(1+c^{L}\right)+\alpha\left(c^{H}-c^{L}\right)}{1+g+\left(1+c^{L}\right)+\alpha\left(c^{H}-c^{L}\right)}\right] \\
& =\frac{\rho q \alpha(1+g)(q-1)\left(c^{H}-c^{L}\right)}{\left[(1+g)+\left(1+c^{L}\right)\right]\left[1+g+\left(1+c^{L}\right)+\alpha\left(c^{H}-c^{L}\right)\right]} \\
& =\frac{\rho q(1+g)}{\left(1+g+\chi_{1}\right)\left[(1+g)+\left(1+c^{L}\right)\right]} \alpha(q-1)\left(c^{H}-c^{L}\right) .
\end{aligned}
$$

Similarly, the uniform contribution rate for the high type minus the original uniform contribution is

$$
\begin{aligned}
P^{U, H}-P^{U} & =\rho q\left[\frac{(1+g) q+\left(1+c^{H}\right)}{(1+g)+\left(1+c^{H}\right)}-\frac{(1+g) q+\chi_{1}}{1+g+\chi_{1}}\right] \\
& =\rho q\left[\frac{(1+g) q+\left(1+c^{H}\right)}{(1+g)+\left(1+c^{H}\right)}-\frac{(1+g) q+\left(1+c^{H}\right)+(1-\alpha)\left(c^{L}-c^{H}\right)}{1+g+\left(1+c^{H}\right)+(1-\alpha)\left(c^{L}-c^{H}\right)}\right] \\
& =\frac{\rho q(1-\alpha)(1+g)(q-1)\left(c^{L}-c^{H}\right)}{\left[(1+g)+\left(1+c^{H}\right)\right]\left[1+g+\left(1+c^{H}\right)+(1-\alpha)\left(c^{L}-c^{H}\right)\right]} \\
& =\frac{\rho q(1+g)}{\left(1+g+\chi_{1}\right)\left[(1+g)+\left(1+c^{H}\right)\right]}(1-\alpha)(q-1)\left(c^{L}-c^{H}\right) .
\end{aligned}
$$

\section{Closed Pension Fund with Two Remaining Working Generations}

When there is no new inflow and there are only two working generations left in the pension fund at time $t=n-2$, the youngest generation pays the following subsidy

$$
\begin{aligned}
& \left(u_{n-1, n-2}^{H} w_{n-1, n-2}^{H}+u_{n-1, n-2}^{L} w_{n-1, n-2}^{L}\right)\left(P^{U}-P_{n-1}\right) \\
& =\rho\left(u_{n-1, n-2}^{H} w_{n-1, n-2}^{H}+u_{n-1, n-2}^{L} w_{n-1, n-2}^{L}\right)\left(\frac{\sum_{i=n-1}^{n}\left[\left(u_{i, n-2}^{H} w_{i, n-2}^{H}+u_{i, n-2}^{L} w_{i, n-2}^{L}\right) K_{i}\right]}{\sum_{i=n-1}^{n}\left(u_{i, n-2}^{H} w_{i, n-2}^{H}+u_{i, n-2}^{L} w_{i, n-2}^{L}\right)}-K_{n-1}\right) \\
& =\frac{\rho\left(u_{n-1, n-2}^{H} w_{n-1, n-2}^{H}+u_{n-1, n-2}^{L} w_{n-1, n-2}^{L}\right)}{\sum_{i=n-1}^{n}\left(u_{i, n-2}^{H} w_{i, n-2}^{H}+u_{i, n-2}^{L} w_{i, n-2}^{L}\right)}\left(u_{n, n-2}^{H} w_{n, n-2}^{H}+u_{n, n-2}^{L} w_{n, n-2}^{L}\right)\left(K_{n}-K_{n-1}\right) .
\end{aligned}
$$

This subsidy is strictly positive for $K_{n}>K_{n-1}$, or equivalently $q<1$. 


\section{References}

Aaron, H. (1966). The social insurance paradox. Canadian Journal of Economics and Political Science, 32(3), 371-374.

Actuarieel Genootschap. (2014). Prognosetafel AG2014. www.ag-ai.nl.

Boeijen, T., Jansen, C., Kortleve, C., \& Tamerus, J. (2006). Leeftijdssolidarieteit in de doorneepremie. In S. V. D. Lecq \& O. Steenbeek (Eds.), Kosten en Baten van Collectieve Pensioensystemen, chapter 7. Dordrecht: Kluwer Academic Publishers.

Bonenkamp, J. (2007). Measuring lifetime redistribution in dutch occupational pensions (p. 81). CPB discussion paper.

Bovenberg, A., Mackenbach, J., \& Mehlkopf, R. (2006). Een eerlijk en vergrijzingbestendig ouderdomspensioen. ESB, 91(4490), 648-651.

CBS. (2017). CBS Statline. https://statline.cbs.nl/.

Chen, D., Beetsma, R., Broeders, D., \& Pelsser, A. (2017). Sustainability of participation in collective pension schemes: An option pricing approach. Insurance: Mathematics and Economics, 74, 182-196.

Chen, D. H. J., \& Beetsma, R. M. W. J. (2015). Mandatory participation in occupational pension schemes in the Netherlands and other countries. An update. Discussion paper 10/2015-032, Netspar.

Deelen, A. (2012). Wage-tenure profiles and mobility (p. 198). CPB discussion paper.

de Euwals, R., Graaf-Zijl, M., \& den Ouden, A. (2014). Arbeidsaanbod tot 2060. CPB, Achtergronddocument.

Lever, M., Bonenkamp, J., \& Cox, R. (2013). Voor- en nadelen van de doorsneesystematiek. CPB Notitie.

Lever, M., \& Muns, S. (2017). Effecten afschaffing doorsneesystematiek: een ALM-analyse. CPB. Achtergronddocument.

Lever, M., Van Ewijk, C., Werker, B., \& van Wijnbergen, S. (2017). Overgangseffecten bij afschaffing doorsneesystematiek. CPB Notitie.

OECD. (2001). Private pensions series OECD 2000 private pensions conference. Private pensions series. OECD Publishing.

Ponds, E. H. M., Severinson, C., \& Yermo, J. (2011). Funding in public sector pension plans: International evidence. NBER working paper, (w17082).

Sinn, H. (2000). Why a funded pension system is needed and why it is not needed. International Tax and Public Finance, 7(4), 389-410.

Sutrisna, J. (2010). De huidige doorsneepremie in de verplichtstelling: een perverse solidariteit? www. aectueel.nl.

Van Ewijk, C. (2017). Doorsneeprobleem en heterogene fondsen: een analytische benadering. www.netsp ar.nl.

Werker, B. (2017). Transitielast en premievrijval bij introductie degressieve opbouw. Tilburg: Mimeo Tilburg University.

Westerhout, E., Bonenkamp, J., \& Broer, P. (2014). Collective versus individual pension schemes: A welfare-theoretical perspective. Netspar discussion paper, (10/2014-045).

Publisher's Note Springer Nature remains neutral with regard to jurisdictional claims in published maps and institutional affiliation 


\section{Affiliations}

Damiaan H. J. Chen ${ }^{1,2,4}$. Sweder J. G. van Wijnbergen ${ }^{1,2,3,5}$

Damiaan H. J. Chen

D.H.J.Chen@UvA.nl

1 Amsterdam School of Economics, University of Amsterdam, Roeterstraat 11, 1018 WB Amsterdam, The Netherlands

2 DNB, Amsterdam, The Netherlands

3 Tinbergen Institute, Amsterdam, The Netherlands

4 Netspar, Tilburg, The Netherlands

5 CEPR, London, UK 